\title{
Heteroatom substitution effect on electronic structures, photophysical properties, and excited-state intramolecular proton transfer processes of 3-hydroxyflavone and its analogues: A TD-DFT study
}

\author{
Chattarika Sukpattanacharoen $^{\text {a, b }}$, Rusrina Salaeh ${ }^{\text {a, b }}$, Vinich Promarak ${ }^{c}$, Daniel Escudero ${ }^{d}$, Nawee Kungwan ${ }^{\text {a, e, * }}$ \\ a Department of Chemistry, Faculty of Science, Chiang Mai University, Chiang Mai, 50200, Thailand \\ ${ }^{b}$ Graduate School, Chiang Mai University, Chiang Mai, 50200, Thailand

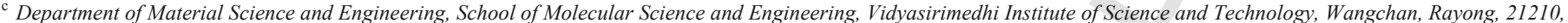 \\ Thailand \\ d Department of Chemistry, KU Leuven, Celestijnenlaan 200F, B-3001 Leuven, Belgium \\ ¿ Center of Excellence in Materials Science and Technology, Chiang Mai University, Chiang Mai, 50200, Thailand
}

\section{A R T I C L E I N F O}

Article history:

Received 19 March 2019

Received in revised form 20 May 2019

Accepted 27 May 2019

Available online $\mathrm{xxx}$

Keywords:

Excited state intramolecular proton transfer (ESIPT)

3-Hydroxyflavone derivatives

Heteroatom effect

TD-DFT

\begin{abstract}
A B S T R A C T
The effects of the electron-donating capacity altered by heteroatom substituents on the electronic structures, photophysical properties, and excited-state intramolecular proton transfer (ESIPT) processes of 3HX analogues (3HF, 3HQ, 3HTF, and $3 \mathrm{HSO}$ where $\mathrm{X}=\mathrm{O}, \mathrm{NH}, \mathrm{S}$, and $\mathrm{SO}_{2}$, respectively) have been investigated by both static calculations and dynamic simulations using density functional theory (DFT) and time-dependent DFT (TD-DFT) methods at B3LYP/TZVP level for ground state $\left(\mathrm{S}_{0}\right)$ and excited-state $\left(\mathrm{S}_{1}\right)$, respectively. The static results indicate that the intramolecular hydrogen bonds of all molecules are strengthened in the $\mathrm{S}_{1}$, confirmed by the red-shift of IR vibrational spectra and the topology analysis. Heteroatom substitutions cause the red-shift on enol absorption and keto emission spectra of 3HX with relatively larger Stoke shift corresponding to their HOMO-LUMO gaps compared with that of 3HF. Frontier molecular orbitals (MOs) show that upon the photoexcitation, the charge redistribution between the proton donor and proton acceptor groups have induced the ESIPT process. Moreover, the potential energy curves (PECs) of proton transfer (PT) processes of all molecules reveal that the PT processes of all molecules are most likely to proceed in the $\mathrm{S}_{1}$ state because of low barriers and exothermic reaction. The chance of ESIPT for all molecules is in this order: $3 \mathrm{HSO}>3 \mathrm{HTF}$ $>3 \mathrm{HF}>3 \mathrm{HQ}$. The results of dynamic simulations confirm that the ESIPT processes of all molecules easily occur with the ultrafast time scale $(48,55,60,70$ fs for $3 \mathrm{HSO}, 3 \mathrm{HTF}, 3 \mathrm{HF}$, and $3 \mathrm{HQ}$, respectively). Furthermore, the PT time is anti-correlated with the electronegativity of heteroatoms in 3HX, supported by Mulliken analysis. The ESIPT process of $3 \mathrm{HSO}$ is the fastest among $3 \mathrm{HX}$ in accordance with its highest intramolecular hydrogen bond strength, lowest PT barrier, and highest exothermic reaction. Nevertheless, after the ESIPT is complete, the twisted structure of $3 \mathrm{HSO}$ has initiated the conical intersection, leading to no keto emission observed in the experiment.
\end{abstract}

\section{Introduction}

Organic bifunctional molecules with an intramolecular hydrogen bonding, connected by proton donors such as $-\mathrm{OH}$ or $-\mathrm{NH}_{2}$ groups and proton acceptors, for example, $-\mathrm{C}=\mathrm{O}$ or $-\mathrm{N}=$ groups, can undergo an excited-state intramolecular proton transfer (ESIPT) process $[1,2]$. The ESIPT process is a keto-enol tautomerization, which is driven by the charge redistribution between the proton donor and the proton acceptor groups upon electronic excitation, described by the four-level photocycle of the ESIPT process (Scheme 1). Typically, the ESIPT process starts from photoexcitation of enol (E) form in the ground state to the excited state, the redistribution of electronic charge takes place, resulting in greater acidity of the proton donor

\footnotetext{
* Corresponding author. Department of Chemistry, Faculty of Science, Chiang Mai University, Chiang Mai, 50200, Thailand.

Email address: naweekung@gmail.com (N. Kungwan)
}

and the basicity of the proton acceptor of excited enol ( $\left.E^{*}\right)$ form [3-5]. As a result, a rapid proton transfer (PT) process occurs via the intramolecular hydrogen bonding from the proton donor to the proton acceptor which leads to the formation of excited keto $\left(\mathrm{K}^{*}\right)$ form. After that, the $\mathrm{K}^{*}$ form returns to the electronic ground state and releases a fluorescence. Since its keto (K) form is not thermodynamically stable, a back-proton transfer (BPT) usually occurs to its initial position (E form) [6]. This four-level photocycle brings the totally different electronic structures between the enol and keto forms, leading to unique photophysical properties as the dual emission and large Stokes shift ( 200 nm) without self-absorption [6] which are useful characters for a lot of applications such as in fundamental photophysical dynamics studies, optoelectronic devices and laser application [2], light-emitting diodes [7] and especially in fluorescent probes [8,9].

Generally, the fluorescent probes in biological systems require highly sensitive to environmental and specific binding to analyst in 


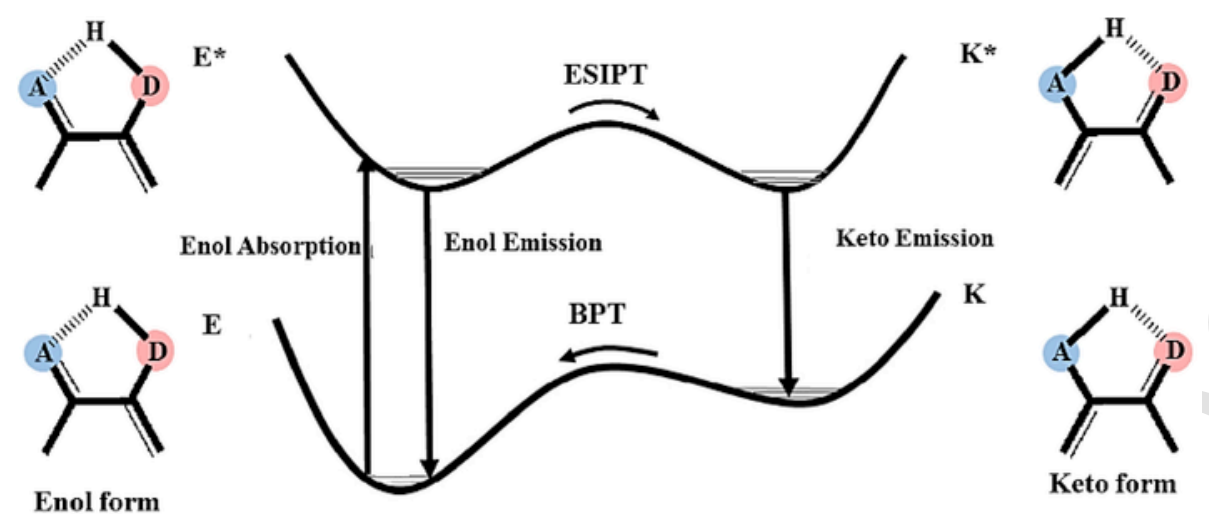

D : Proton donor $\left(-\mathrm{OH}\right.$ or $\left.-\mathrm{NH}_{2}\right)$

A : Proton acceptor $(-\mathrm{C}=\mathrm{O}$ or $-\mathrm{N}=)$ 
Journal of Molecular Structure xxx (xxxx) xxx-xxx 


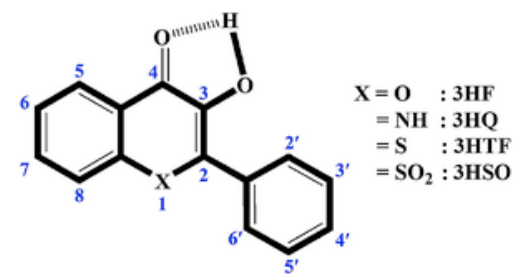

Fig. 1. Molecular structures of $3 \mathrm{HX}$ analogues, where $\mathrm{X}=\mathrm{O}, \mathrm{NH}, \mathrm{S}$, and $\mathrm{SO}_{2}$ namely $3 \mathrm{HF}, 3 \mathrm{HQ}, 3 \mathrm{HTF}$, and $3 \mathrm{HSO}$.

cells $[10,11]$. The desirable characters for probing specific targets using chromophores in cells and tissue samples include absorption of visible light, emission at long wavelengths (preferably in red or near-infrared) with high fluorescence intensity [10-14]. Successful fluorescent probes have been reported such as the derivatives of fluorescein [15], rhodamine [16], coumarin [17,18], boron-dipyrromethene (BODIPY) [19], and cyanine [20]. Among the reported fluorescent probes, a flavonol family with ESIPT chromophore has emerged as a new potential class because of its unique photophysical properties and abundance in nature [21-24]. 3-Hydroxyflavone (3HF), one of the flavonol family as shown in Fig. 1 (when $\mathrm{X}=\mathrm{O}$ ), has been not only used as fluorescent probes but also as a model molecule to study the ESIPT process due to its unique large Stokes shift (190 nm) [25] and dual emissions [26-29]. However, a wider application of $3 \mathrm{HF}$ as a fluorescent probe has been limited due to its enol absorption and keto emission not being in the longer wavelength, the proper ratio of dual emission $\left(\mathrm{N}^{*} / \mathrm{I}^{*}\right)$ and low intensity of fluorescence.

$3 \mathrm{HF}$ derivatives with improved photophysical properties have been both experimentally and theoretically reported by many researchers [30-37]. Various 3HF derivatives can be obtained by substitutions of the electron donating groups (at the position 4', 2, 6, and 7 of 3HF). The introduction of electron donor at the position $4^{\prime}$ of $3 \mathrm{HF}$ and replacing phenyl group with furanyl, thiophenyl, and benzofuranyl at position 2 not only shifts the enol absorption and keto emission spectra to longer wavelengths, but also strongly modulates the ESIPT behavior, resulting in increase of the ratio of the dual emission $\left(\mathrm{N}^{*} / \mathrm{I}^{*}\right)$, as well as increase in intensity of fluorescence. By introduction of fused furan heterocycle (2-aryl-3-hydroxyfyrano[3,2-g]chromone) at position 6 and 7 of $3 \mathrm{HF}[38,39]$, the highly polarizable $\pi$-electron has improved photophysical properties in term of red-shifting of enol absorption and keto emission, leading to larger Stokes shift, and higher fluorescent intensity of $3 \mathrm{HF}$ derivatives with $3 \mathrm{HF}$. For other $3 \mathrm{HF}$ derivatives, the substitutions of pyrazole and pyrrole at position 2 of $3 \mathrm{HF}$, however, shift the enol absorption and keto emission to shorter wavelengths and decrease the fluorescent intensity, compared with $3 \mathrm{HF}$ [40-42].

As mentioned above, the substituent effects on the electronic structures and photophysical properties as well as the ESIPT behavior of $3 \mathrm{HF}$ derivatives have been intensively investigated by many researchers. So far, there are just a few reports on the heteroatom substitution effect on the electronic and photophysical properties as well as the occurrence of the ESIPT process. The nitrogen heteroatom substituted 3HF, namely 3-hydroxyquinolone (3HQ), was synthesized by Feng et al. [43] and their experimental results indicated that the higher electronegativity of the nitrogen atom in 3HQ reduced the Stokes shift, compared with that of $3 \mathrm{HF}$. For other analogues of $3 \mathrm{HF}$, the sulfur heteroatom substituted 3HF, 3-hydroxythioflavone (3HTF) was synthesized and its photophysical properties were characterized by Meng et al. [44] and the lower electronegativity of the sulfur heteroatom in $3 \mathrm{HTF}$ was somehow found to increase the Stokes shift, compared with those of 3HF and 3HQ. Moreover, the photophysical properties and the chance of the ESIPT process for 3 HTF was inves-
Table 1

Calculated maximum wavelengths of enol absorption $\left(\lambda_{\max }\right)$, oscillator strength $(f)$, and the deviation between the calculated and experimental wavelength $(\Delta \lambda)$ of $3 \mathrm{HF}, 3 \mathrm{HTF}$, and $3 \mathrm{HSO}$ in cyclohexane and $3 \mathrm{HQ}$ in toluene computed using various TD-DFT methods with TZVP basis set.

\begin{tabular}{|c|c|c|c|c|}
\hline TD-DFT & $\begin{array}{l}\lambda_{\max } \\
(\mathrm{nm})\end{array}$ & $f$ & $\begin{array}{l}\text { MOs (\% } \\
\text { Contribution) }\end{array}$ & $\begin{array}{l}\Delta \lambda \\
(\mathrm{nm})\end{array}$ \\
\hline \multicolumn{5}{|l|}{$3 \mathrm{HF}$} \\
\hline Experiment & $340[25]$ & & & \\
\hline TD-B3LYP & 343 & 0.513 & $\begin{array}{l}\text { HOMO } \rightarrow \text { LUMO } \\
(98 \%)\end{array}$ & 3 \\
\hline TD-PBE0 & 333 & 0.488 & $\begin{array}{l}\text { HOMO } \rightarrow \text { LUMO } \\
(98 \%)\end{array}$ & -7 \\
\hline TD-M06-2X & 304 & 0.549 & $\begin{array}{l}\text { HOMO } \rightarrow \text { LUMO } \\
(97 \%)\end{array}$ & -36 \\
\hline TD-CAM-B3LYP & 309 & 0.543 & $\begin{array}{l}\text { HOMO } \rightarrow \text { LUMO } \\
(96 \%)\end{array}$ & -31 \\
\hline TD-LC-BLYP & 278 & 0.598 & $\begin{array}{l}\text { HOMO } \rightarrow \text { LUMO } \\
(90 \%)\end{array}$ & -62 \\
\hline $\begin{array}{l}\text { TD-LC-BLYP } \\
\qquad(\mu=0.200)\end{array}$ & 294 & 0.650 & $\begin{array}{l}\text { HOMO } \rightarrow \text { LUMO } \\
(91 \%)\end{array}$ & -46 \\
\hline $\begin{array}{l}\text { TD-LC- } \omega \text { PBE } \\
\quad(\mu=0.141)\end{array}$ & 304 & 0.612 & $\begin{array}{l}\text { HOMO } \rightarrow \text { LUMO } \\
(93 \%)\end{array}$ & -36 \\
\hline \multicolumn{5}{|l|}{$3 \mathrm{HQ}$} \\
\hline Experiment & 371 [43] & & & \\
\hline TD-B3LYP & 362 & 0.228 & $\begin{array}{l}\text { HOMO } \rightarrow \text { LUMO } \\
(97 \%)\end{array}$ & -9 \\
\hline TD-PBE0 & 361 & 0.232 & $\begin{array}{l}\text { HOMO } \rightarrow \text { LUMO } \\
(97 \%)\end{array}$ & -10 \\
\hline TD-M06-2X & 356 & 0.221 & $\begin{array}{l}\text { HOMO } \rightarrow \text { LUMO } \\
(97 \%)\end{array}$ & -15 \\
\hline TD-CAM-B3LYP & 356 & 0.221 & $\begin{array}{l}\text { HOMO } \rightarrow \text { LUMO } \\
(97 \%)\end{array}$ & -15 \\
\hline TD-LC-BLYP & 349 & 0.218 & $\begin{array}{l}\text { HOMO } \rightarrow \text { LUMO } \\
(97 \%)\end{array}$ & -22 \\
\hline $\begin{array}{l}\text { TD-LC-BLYP } \\
\qquad(\mu=0.200)\end{array}$ & 365 & 0.249 & $\begin{array}{l}\text { HOMO } \rightarrow \text { LUMO } \\
(98 \%)\end{array}$ & -6 \\
\hline $\begin{array}{l}\text { TD-LC- } \omega \text { PBE } \\
\quad(\mu=0.141)\end{array}$ & 366 & 0.235 & $\begin{array}{l}\text { HOMO } \rightarrow \text { LUMO } \\
(97 \%)\end{array}$ & -5 \\
\hline \multicolumn{5}{|l|}{$3 \mathrm{HTF}$} \\
\hline Experiment & $380[44]$ & & & \\
\hline TD-B3LYP & 371 & 0.264 & $\begin{array}{l}\text { HOMO } \rightarrow \text { LUMO } \\
(97 \%)\end{array}$ & -9 \\
\hline TD-PBE0 & 370 & 0.270 & $\begin{array}{l}\text { HOMO } \rightarrow \text { LUMO } \\
(97 \%)\end{array}$ & -10 \\
\hline TD-M06-2X & 364 & 0.257 & $\begin{array}{l}\text { HOMO } \rightarrow \text { LUMO } \\
(97 \%)\end{array}$ & -16 \\
\hline TD-CAM-B3LYP & 364 & 0.253 & $\begin{array}{l}\text { HOMO } \rightarrow \text { LUMO } \\
(97 \%)\end{array}$ & -16 \\
\hline TD-LC-BLYP & 357 & 0.245 & $\begin{array}{l}\text { HOMO } \rightarrow \text { LUMO } \\
(97 \%)\end{array}$ & -23 \\
\hline $\begin{array}{l}\text { TD-LC-BLYP } \\
\qquad(\mu=0.200)\end{array}$ & 375 & 0.287 & $\begin{array}{l}\text { HOMO } \rightarrow \text { LUMO } \\
(97 \%)\end{array}$ & -5 \\
\hline $\begin{array}{l}\text { TD-LC- } \omega \text { PBE } \\
\qquad(\mu=0.141)\end{array}$ & 376 & 0.272 & $\begin{array}{l}\text { HOMO } \rightarrow \text { LUMO } \\
(97 \%)\end{array}$ & -4 \\
\hline \multicolumn{5}{|l|}{$3 \mathrm{HSO}$} \\
\hline Experiment & 370 [44] & & & \\
\hline TD-B3LYP & 377 & 0.189 & $\begin{array}{l}\text { HOMO } \rightarrow \text { LUMO } \\
(98 \%)\end{array}$ & 12 \\
\hline TD-PBE0 & 364 & 0.208 & $\begin{array}{l}\text { HOMO } \rightarrow \text { LUMO } \\
(97 \%)\end{array}$ & 11 \\
\hline TD-M06-2X & 329 & 0.175 & $\begin{array}{l}\text { HOMO } \rightarrow \text { LUMO } \\
(67 \%)\end{array}$ & -41 \\
\hline TD-CAM-B3LYP & 332 & 0.172 & $\begin{array}{l}\text { HOMO } \rightarrow \text { LUMO } \\
(84 \%)\end{array}$ & -38 \\
\hline TD-LC-BLYP & 290 & 0.224 & $\begin{array}{l}\text { HOMO } \rightarrow \text { LUMO } \\
(59 \%)\end{array}$ & -90 \\
\hline $\begin{array}{l}\text { TD-LC-BLYP } \\
\quad(\mu=0.200)\end{array}$ & 398 & 0.219 & $\begin{array}{l}\text { HOMO } \rightarrow \text { LUMO } \\
(90 \%)\end{array}$ & 28 \\
\hline $\begin{array}{l}\text { TD-LC- } \omega \text { PBE } \\
\quad(\mu=0.141)\end{array}$ & 429 & 0.159 & $\begin{array}{l}\text { HOMO } \rightarrow \text { LUMO } \\
(93 \%)\end{array}$ & 59 \\
\hline
\end{tabular}

tigated by DFT and TD-DFT methods by Sun et al. [45] and their results indicate that the substitution of sulfur heteroatom cause the red-shift of enol absorption and keto emission of $3 \mathrm{HTF}$ to longer wavelengths with larger Stokes shift, compared with those of $3 \mathrm{HF}$ and 

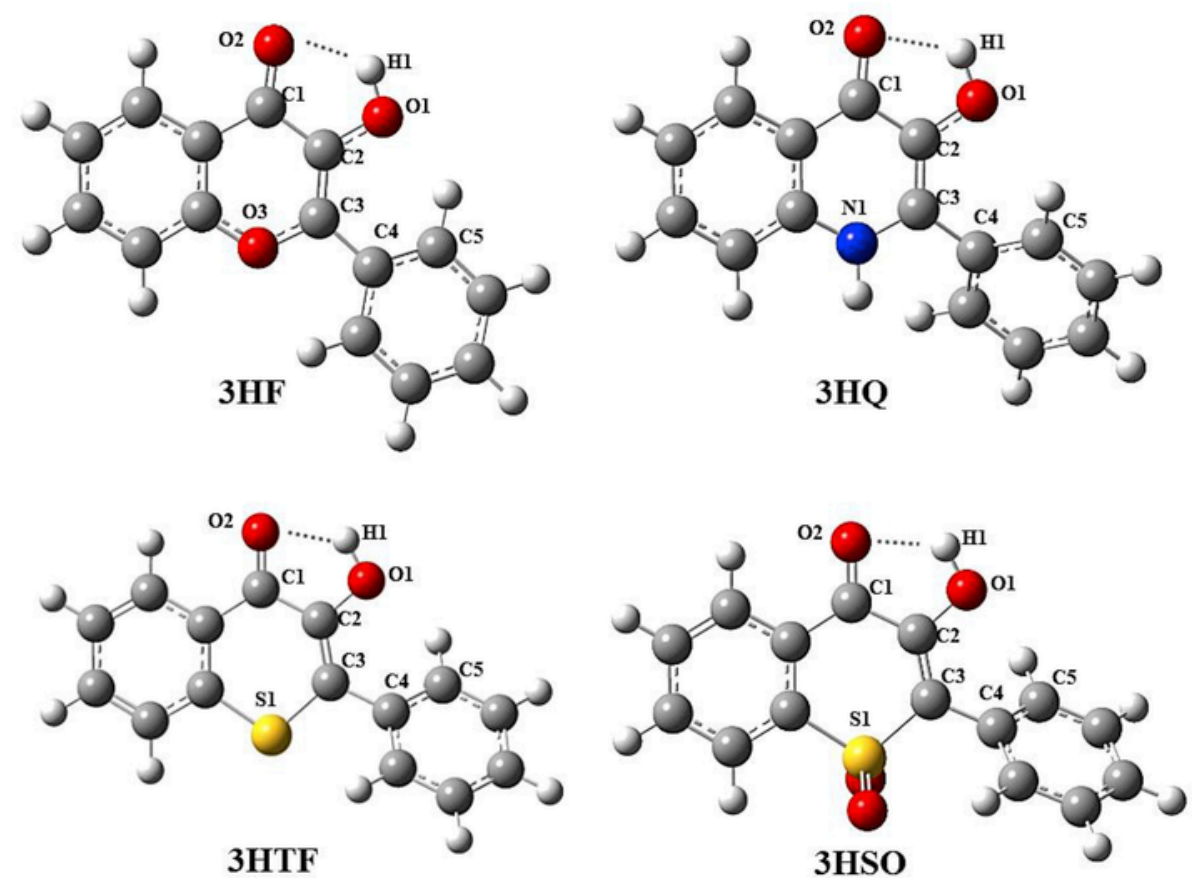

Fig. 2. Optimized enol form in the $\mathrm{S}_{0}$ state of $3 \mathrm{HF}, 3 \mathrm{HTF}$, and $3 \mathrm{HSO}$ in cyclohexane and $3 \mathrm{HQ}$ in toluene computed at B3LYP/TZVP level. Intramolecular hydrogen bond distances are shown as dashed lines.

Table 2

Covalent bonds $(\mathrm{O} 1-\mathrm{H} 1)$, intramolecular hydrogen bonds $(\mathrm{O} 2 \cdots \mathrm{H} 1)$, the distances between heavy atoms $(\mathrm{O} 1 \cdots \mathrm{O} 2)$ and selected dihedral angles $\left({ }^{\circ}\right)$ of enol form of $3 \mathrm{HF}$, $3 \mathrm{HTF}$, and $3 \mathrm{HSO}$ in cyclohexane and $3 \mathrm{HQ}$ in toluene computed at TD-B3LYP/TZVP level.

\begin{tabular}{|c|c|c|c|c|c|c|c|c|}
\hline & $3 \mathrm{HF}$ & & $3 \mathrm{HQ}$ & & $3 \mathrm{HTF}$ & & $3 \mathrm{HSO}$ & \\
\hline & $\mathrm{S}_{0}$ state & $\mathrm{S}_{1}$ state & $\mathrm{S}_{0}$ state & $\mathrm{S}_{1}$ state & $\mathrm{S}_{0}$ state & $\mathrm{S}_{1}$ state & $\mathrm{S}_{0}$ state & $\mathrm{S}_{1}$ state \\
\hline \multicolumn{9}{|l|}{ Distance $(\AA)$} \\
\hline $\mathrm{O} 1-\mathrm{H} 1$ & 0.978 & 0.999 & 0.980 & 0.995 & 0.981 & 1.008 & 0.978 & 1.024 \\
\hline $\mathrm{O} 2 \cdots \mathrm{H} 1$ & 2.012 & 1.847 & 1.994 & 1.888 & 1.909 & 1.730 & 1.934 & 1.648 \\
\hline $\mathrm{O} 1 \cdots \mathrm{O} 2$ & 2.625 & 2.541 & 2.620 & 2.561 & 2.554 & 2.473 & 2.556 & 2.433 \\
\hline \multicolumn{9}{|l|}{ Bond angle $\left({ }^{\circ}\right)$} \\
\hline \multicolumn{9}{|l|}{ Dihedral angle $\left({ }^{\circ}\right)$} \\
\hline $\mathrm{O} 1 \mathrm{C} 1 \mathrm{C} 2 \mathrm{X} 1$ & 0.7 & 1.1 & 1.5 & 2.8 & 0.1 & 10.6 & 2.9 & 13.5 \\
\hline $\mathrm{O} 1 \mathrm{C} 1 \mathrm{C} 5 \mathrm{O} 2$ & 0.3 & 0.5 & 0.6 & 1.6 & 0.7 & 8.2 & 0.5 & 8.3 \\
\hline $\mathrm{C} 2 \mathrm{C} 3 \mathrm{C} 4 \mathrm{C} 5$ & 15.8 & 0.06 & 40.2 & 26.8 & 44.6 & 23.6 & 53.6 & 30.1 \\
\hline
\end{tabular}

The $\mathrm{X}$ represents the heavy atoms of the investigated molecules (O3, N1, and $\mathrm{S} 1$ as shown in Fig. 2).

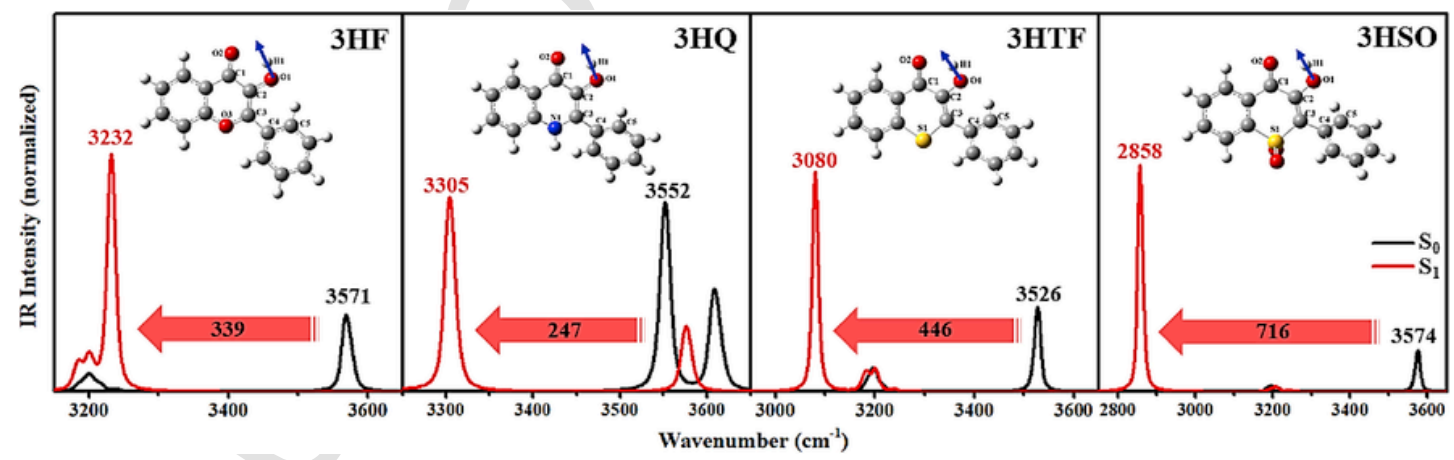

Fig. 3. The simulated IR spectra of enol form of all molecules both in $\mathrm{S}_{0}$ state (black line) and $\mathrm{S}_{1}$ state (red line). The vibrational bands of the O1-H1 stretching modes both in $\mathrm{S}_{0}$ and $\mathrm{S}_{1}$ states are labelled as black and red, respectively. (For interpretation of the references to colour in this figure legend, the reader is referred to the Web version of this article.) 
Table 3

Selected bond critical point parameters (in a.u.) related to the hydrogen bonds of enol forms for all molecules.

\begin{tabular}{|c|c|c|c|c|c|c|c|}
\hline Molecule & $\rho(\mathrm{r})$ & $\mathrm{H}(\mathrm{r})$ & $\mathrm{G}(\mathrm{r})$ & $\nabla^{2} \rho(\mathrm{r})$ & DI & $V(\mathrm{r})$ & $\mathrm{E}_{\mathrm{HB}}$ \\
\hline $3 \mathrm{HF}$ & 0.038 & -0.0025 & 0.034 & 0.125 & 0.092 & -0.036 & 0.018 \\
\hline 3HQ & 0.035 & -0.0011 & 0.031 & 0.120 & 0.086 & -0.032 & 0.016 \\
\hline $3 \mathrm{HTF}$ & 0.049 & -0.0083 & 0.043 & 0.138 & 0.112 & -0.051 & 0.026 \\
\hline $3 \mathrm{HSO}$ & 0.056 & -0.0146 & 0.050 & 0.142 & 0.129 & -0.055 & 0.028 \\
\hline
\end{tabular}

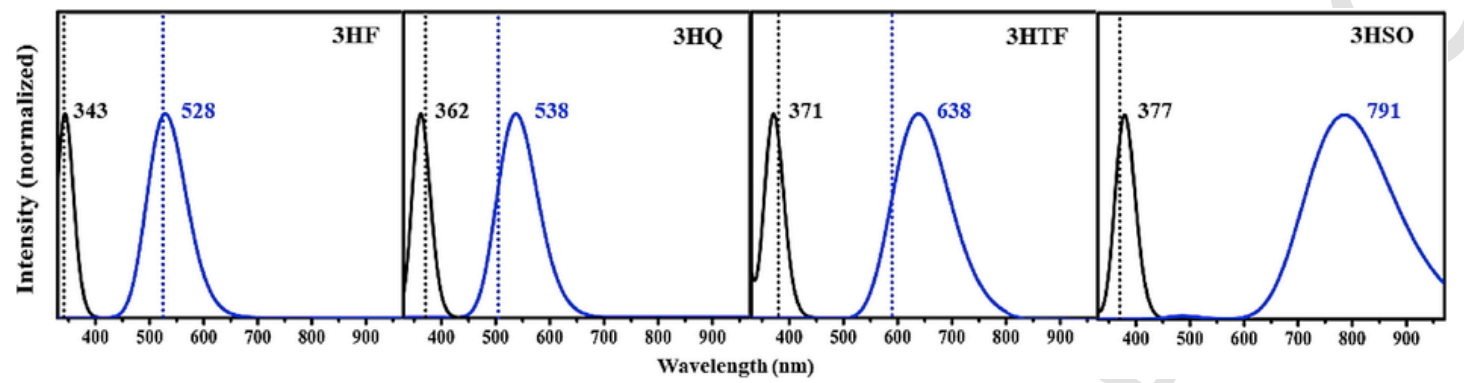

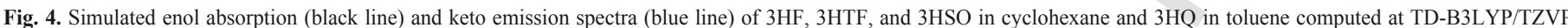
level. (For interpretation of the references to colour in this figure legend, the reader is referred to the Web version of this article.)

Table 4

Simulated enol absorption maximum wavelengths $\left(\lambda_{\max }\right)$, keto emission maximum wavelengths $\left(\lambda_{\text {emiss }}\right)$, oscillator strength $(f)$, molecular orbitals (MOs) contribution, and Stokes shifts of $3 \mathrm{HF}, 3 \mathrm{HTF}$, and $3 \mathrm{HSO}$ in cyclohexane and $3 \mathrm{HQ}$ in toluene computed at TD-B3LYP/TZVP level.

\begin{tabular}{|c|c|c|c|c|c|c|}
\hline \multirow[t]{2}{*}{ Molecule } & \multicolumn{3}{|c|}{ Enol Absorption } & \multicolumn{2}{|c|}{ Keto Emission } & \multirow[t]{2}{*}{$\begin{array}{l}\text { Stokes } \\
\text { shift } \\
(\mathrm{nm})\end{array}$} \\
\hline & $\begin{array}{l}\lambda_{\max } \\
(\mathrm{nm})\end{array}$ & $f$ & $\begin{array}{l}\text { MOs (\% } \\
\text { Contribution) }\end{array}$ & $\begin{array}{l}\lambda_{\text {emiss }} \\
(\mathrm{nm})\end{array}$ & $f$ & \\
\hline $3 \mathrm{HF}$ & 343 & 0.513 & $\begin{array}{l}\text { HOMO } \rightarrow \\
\text { LUMO }(98 \%)\end{array}$ & 528 & 0.446 & 185 \\
\hline 3HQ & 362 & 0.228 & $\begin{array}{l}\text { HOMO } \rightarrow \\
\text { LUMO }(97 \%)\end{array}$ & 538 & 0.302 & 176 \\
\hline $3 \mathrm{HTF}$ & 371 & 0.264 & $\begin{array}{l}\text { HOMO } \rightarrow \\
\text { LUMO }(97 \%)\end{array}$ & 638 & 0.282 & 267 \\
\hline $3 \mathrm{HSO}$ & 377 & 0.189 & $\begin{array}{l}\text { HOMO } \rightarrow \\
\text { LUMO }(98 \%)\end{array}$ & 791 & 0.156 & 414 \\
\hline
\end{tabular}

3HQ. Sulfone heteroatom substitution of 3HF, namely 3-hydroxy-2-phenyl-4H-thiochromen-4-one 1,1-dioxide (3HSO) was reported to have a longer wavelength of enol absorption compared with that of $3 \mathrm{HF}$ however, its keto emission was not observed, implying that the ESIPT process might not take place [44].

Following the requirement of fluorescent probes as longer wavelength of enol absorption and near IR keto emission leading to a larger Stokes shift and high intensity of keto emission, most of the reports have only dealt with the photophysical properties of $3 \mathrm{HF}$ derivatives. Whereas the in-depth insights into the effects of the heteroatom substitution on the electronic structures, photophysical properties, and the chance of the ESIPT process, as well as the PT time of $3 \mathrm{HQ}$, 3HTF, and $3 \mathrm{HSO}$, have not been systematically studied. Nowadays, computational chemistry has become an effective tool not only for obtaining deep information on the electronic and photophysical properties but also predicting useful information where it cannot be accessible by means of experimental methods. Therefore, in this study, we systematically investigate the effect of different heteroatom

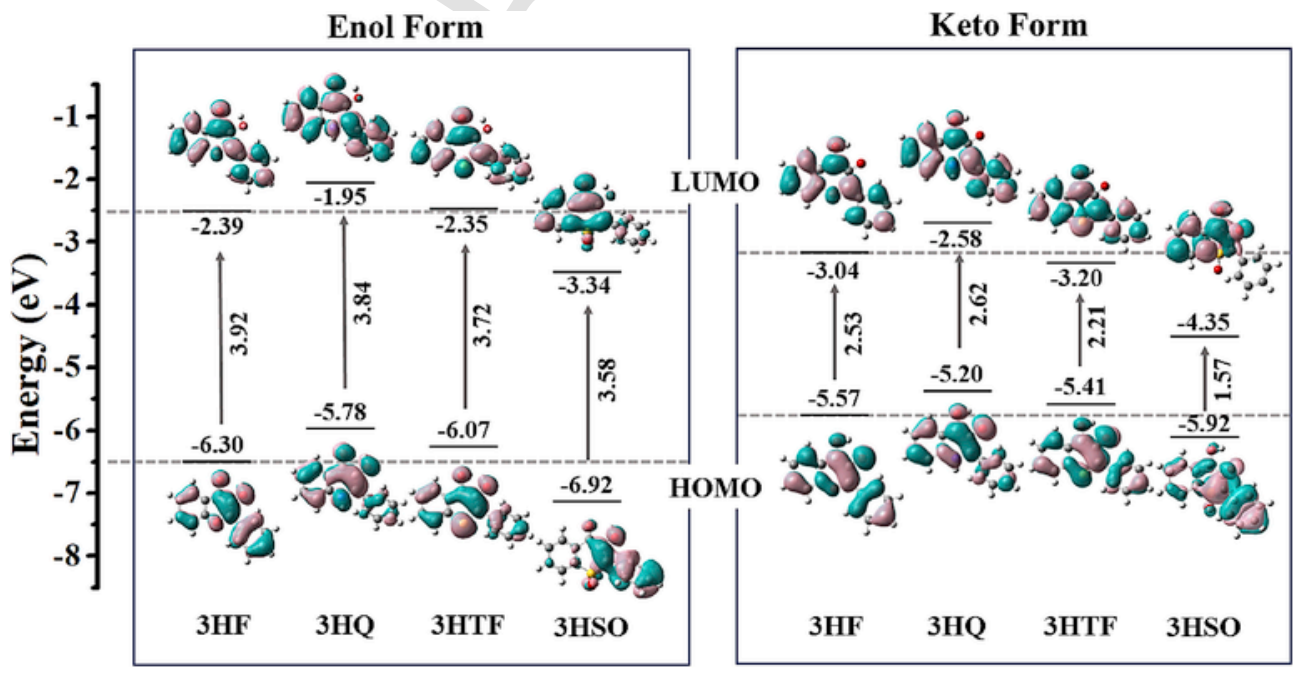

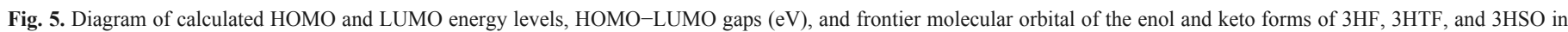
cyclohexane and 3HQ in toluene computed at TD-B3LYP/TZVP level. 


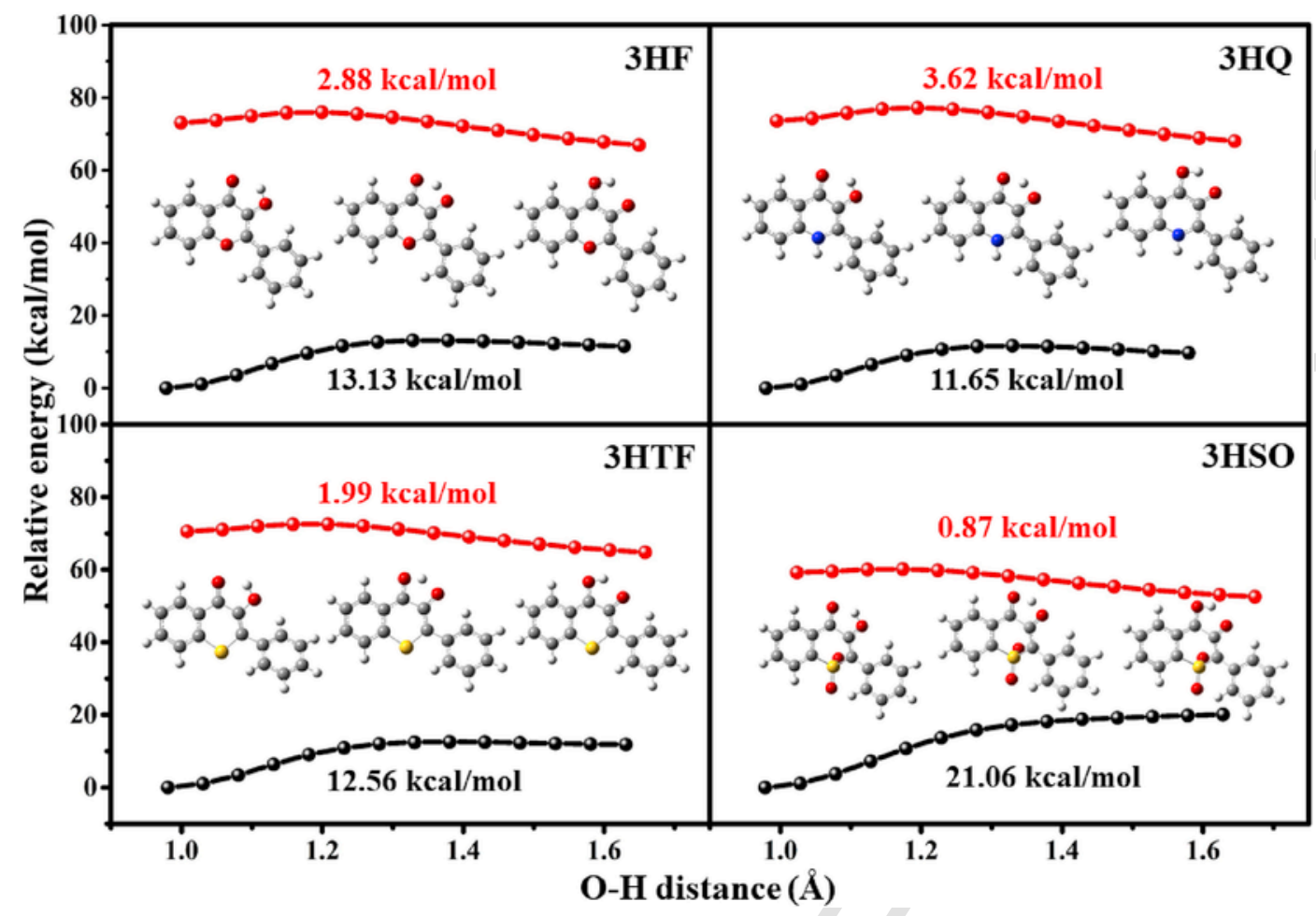

Fig. 6. The potential energy curves (PECs) of PT reactions both in $\mathrm{S}_{0}$ and $\mathrm{S}_{1}$ states of $3 \mathrm{HF}, 3 \mathrm{HTF}$, and $3 \mathrm{HSO}$ in cyclohexane and $3 \mathrm{HQ}$ in toluene computed at TD-B3LYP/TZVP level.

\section{Table 5}

The relative PT barriers and PT reaction energy $\left(\Delta \mathrm{E}_{\mathrm{rxn}}\right)$ both in $\mathrm{S}_{0}$ and $\mathrm{S}_{1}$ states of $3 \mathrm{HF}$, $3 \mathrm{HTF}$, and $3 \mathrm{HSO}$ in cyclohexane and $3 \mathrm{HQ}$ in toluene computed at TD-B3LYP/TZVP level.

\begin{tabular}{lllll}
\hline Molecule & \multicolumn{2}{l}{ PT barrier $(\mathrm{kcal} / \mathrm{mol})$} & \multicolumn{2}{l}{$\Delta \mathrm{E}_{\mathrm{rxn}}(\mathrm{kcal} / \mathrm{mol})$} \\
\hline & $\mathrm{S}_{0}$ state & $\mathrm{S}_{1}$ state & $\mathrm{S}_{0}$ state & $\mathrm{S}_{1}$ state \\
\hline 3HF & 13.13 & 2.88 & 10.89 & -4.81 \\
3HQ & 11.65 & 3.62 & 8.45 & -4.05 \\
3HTF & 12.56 & 1.99 & 11.76 & -7.25 \\
3HSO & 21.06 & 0.87 & 20.95 & -10.26 \\
\hline
\end{tabular}

substitutions on the electronic structures, photophysical properties, and the chance of ESIPT processes of all molecules (3HF, 3HQ, $3 \mathrm{HTF}$, and $3 \mathrm{HSO}$ ) and particularly why $3 \mathrm{HSO}$ does not exhibit keto emission in the experiment. By using density functional theory (DFT) and time-depended DFT (TD-DFT), the electronic structures and the potential energy curves (PECs) along the proton transfer (PT) process of $3 \mathrm{HF}$ and its analogues both in the ground state $\left(\mathrm{S}_{0}\right)$ and the excited-state $\left(\mathrm{S}_{1}\right)$ will be analyzed. Furthermore, the details of dynamics simulations such as PT time, PT probability, and the change of interested dihedral angle during the simulation time, will be also carried out using on-the-fly dynamic simulations.

\section{Computational details}

\subsection{Static calculations}

The $\mathrm{S}_{0}$ state optimizations of enol form of all molecules were carried out using seven DFT methods with various change-correlation functionals, which consist of three hybrid functionals (B3LYP [46], PBE0 [47], and M06-2X [48]) and four long-range corrected hybrid functionals (CAM-B3LYP [49], LC-BLYP [50], LC-BLYP $(\mu=0.200)$ [51], and LC- $\omega \mathrm{PBE}(\mu=0.141)$ [52,53]) with triple- $\zeta$ valence quality with one set of polarization functions (TZVP) basis set [54]. For the hybrid functional, the B3LYP is Hybrid Becke, 3-parameter, Lee-Yang-Parr gradient-corrected correlation potential with $20 \%$ Hartree-Fock (HF) exchange energy. The PBE0 is the mixed functional between Perdew-Burke-Ernzerhof and 25\% HF exchange energy. The M06-2X are the hybrid functional of Truhlar and Zhao and 54\% HF exchange energy. Four long-range correlated hybrid functionals include the CAM-B3LYP, the LC-BLYP, the LC- $\omega$ PBE, which are Handy, Hirao, and Henderson. The LC-BLYP and the $\mathrm{LC}-\omega \mathrm{PBE}$, the damping parameter $\mu$ is set to 0.330 and $0.200 \mathrm{bohr}^{-1}$ for the LC-BLYP and $0.141 \mathrm{bohr}^{-1}$ for the LC- $\omega$ PBE which $\mu$ parameter is the term for correcting long-range interaction to describe via HF exchange. The effect of solvents such as cyclohexane and toluene, corresponding to the experiment $[25,43,44]$, was taken into account by SCRF method through the non-equilibrium and equilibrium polarizable continuum model calculations using the polarizable continuum model (PCM) for all calculation [55]. All optimized structures were confirmed to be local minima by normal mode analysis with all positive frequencies. To reveal the influence of DFT functional on the absorption spectra associated with the electronic transition of the enol form of all molecules, the enol absorption spectra were performed using various TD-DFT methods. The absorption and emission spectra as well as the orbital contributions were generated with GaussSum package [56]. From the method of choice, among seven tested functionals, the most suitable method for reproducing the enol absorption spectra of all molecules is the B3LYP because this method provides the most satisfactory agreement with the experimental data. Moreover, previous studies have been proven that the B3LYP and TD-B3LYP functionals with TZVP basis set are suitable to describe electronic and photophysical properties as well as the PT process of ESIPT molecules [29,57-62]. Therefore, the B3LYP was further em- 


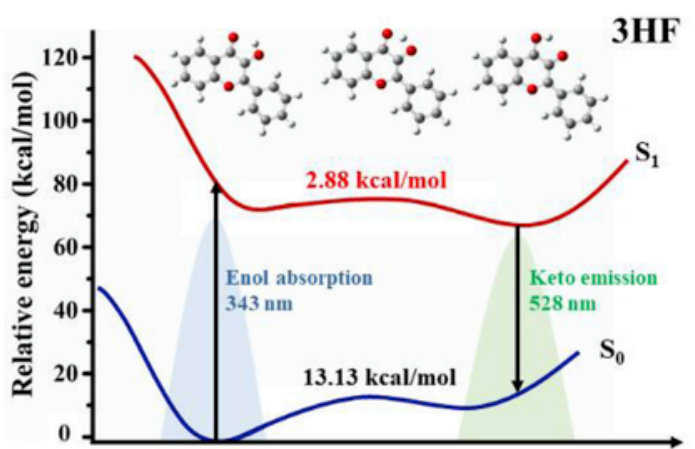

PT reaction coordinate

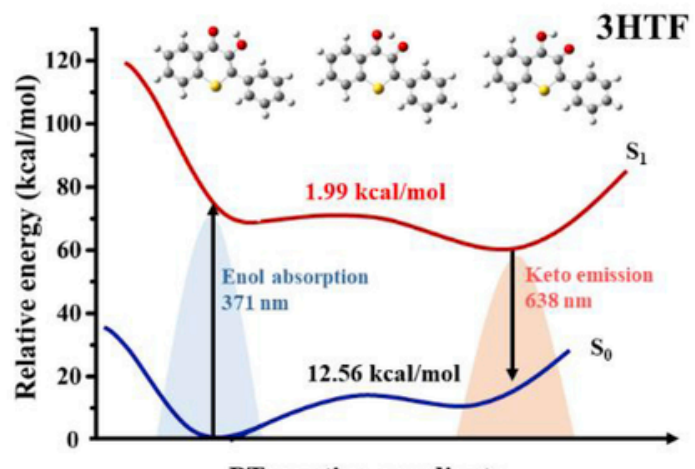

PT reaction coordinate

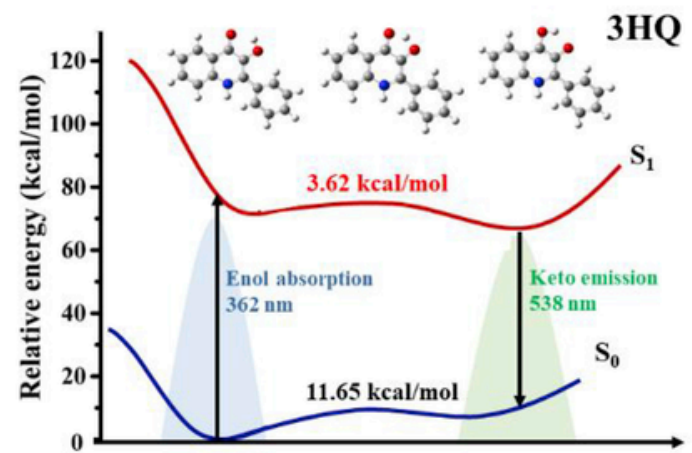

PT reaction coordinate

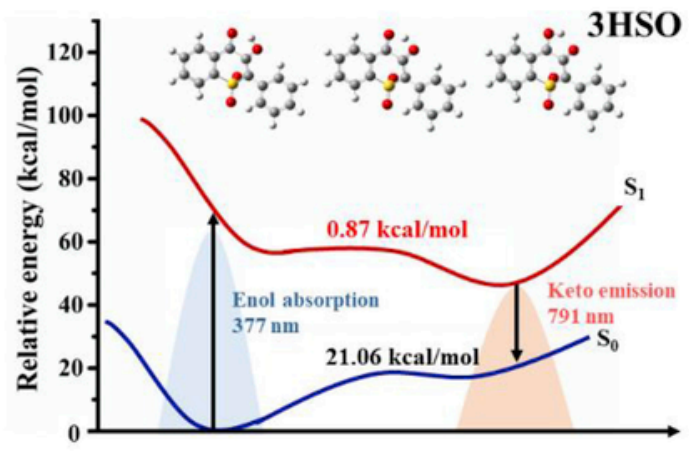

PT reaction coordinate

Fig. 7. The potential energy curves (PECs) of PT reactions and the vertical energies both in the $\mathrm{S}_{0}$ and $\mathrm{S}_{1}$ states of all molecules computed at TD-B3LYP/TZVP level.

Table 6

Summary of the excited-state dynamics simulations performed at the TD-B3LYP/TZVP level.

\begin{tabular}{lllll}
\hline Molecule & Reaction & & PT time (fs) & Probability \\
\hline & ESIPT & No PT & & \\
\hline 3HF & 19 & 6 & $60(47-67)$ & 0.76 \\
3HQ & 6 & 19 & $70(51-150)$ & 0.24 \\
3HTF & 12 & 13 & $55(45-63)$ & 0.48 \\
3HSO & 23 & 2 & $48(42-55)$ & 0.92 \\
\hline
\end{tabular}

ployed to optimize the enol form in the $S_{1}$ state and the keto form both in $\mathrm{S}_{0}$ and the $\mathrm{S}_{1}$ states of all molecules.

The $S_{0}$ and $S_{1}$ state optimizations of enol and keto forms of all molecules were carried out using B3LYP and TD-B3LYP, respectively. The strength of hydrogen bond of all molecules was investigated by the important parameters which involved the ESIPT process, including the $\mathrm{O} 1-\mathrm{H} 1, \mathrm{O} 2 \cdots \mathrm{H} 1$, and $\mathrm{O} 1 \cdots \mathrm{O} 2$ distances, the infrared (IR) spectra of the $\mathrm{O}-\mathrm{H}$ bond both in $\mathrm{S}_{0}$ and the $\mathrm{S}_{1}$ states as well as the topology analysis based on the theory of quantum theory of atoms in molecules (QTAIM) with the tool of Multiwfn [63] which was employed in previous studies $[64,65]$. Calculations of vertical excitation energies were done from the $\mathrm{S}_{0}$ state optimized structure using TD-B3LYP with five low-lying singlet states absorbing transition. Moreover, the keto emissions of all molecules were simulated from the $S_{1}$ state. Furthermore, frontier molecular orbitals (MOs) of all molecules both the enol and keto forms were analyzed to provide information about the charge distribution upon photoexcitation. To future investigate the chance of PT process, the $\mathrm{S}_{0}$ state energy curve (GS-PECs) and the $\mathrm{S}_{1}$ state potential energy curves (ES-PECs) of all molecules along PT process coordinate were scanned by constraining optimizations with fixed the covalent $(\mathrm{O} 1-\mathrm{H} 1)$ bond distance at a series of values. This approach was used in the previous studies and shown to be reliable in providing qualitative energetic pathways for PT process [62,66-70]. In addition, to obtain the thermodynamic information, the ESIPT reaction energies were calculated from the $\mathrm{S}_{1}$ state optimization of keto forms of all molecules. All calculations were performed using Gaussian 09 program package [71].
At 0 fs

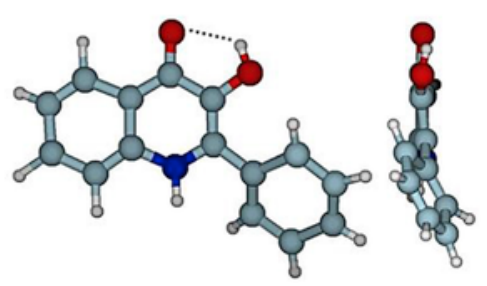

At 70 fs

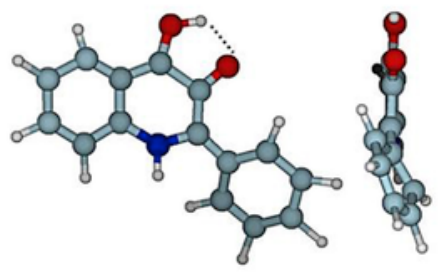

At 150 fs

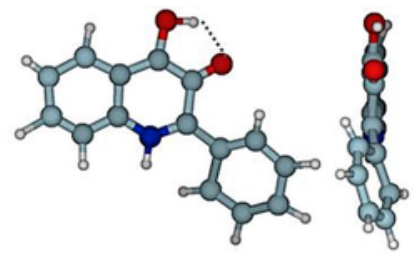

Fig. 8. Snapshots along with the ESIPT dynamic simulations at a different time of 3 HQ (left: front view, right: side view). 

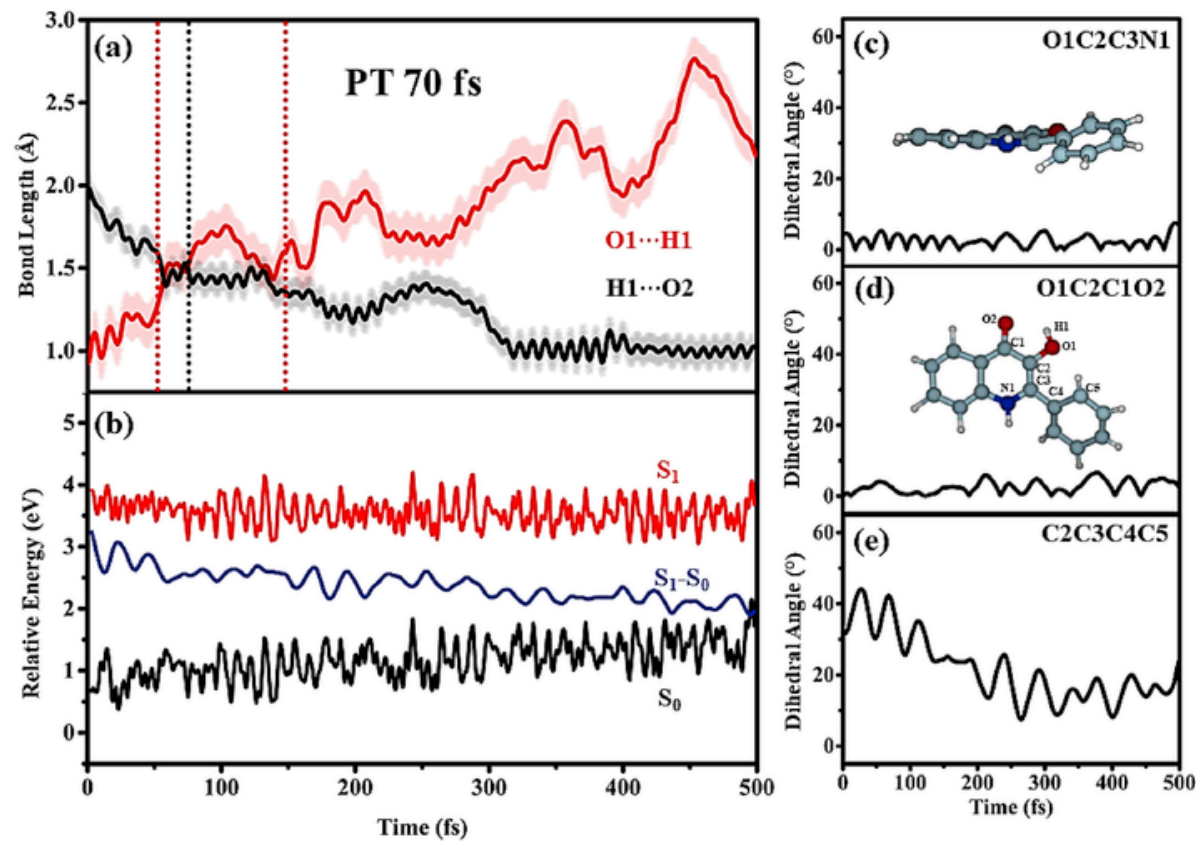

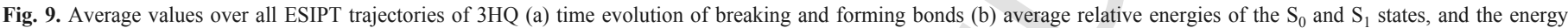
difference between the $\mathrm{S}_{1}$ and $\mathrm{S}_{0}$ states $\left(\mathrm{S}_{1}-\mathrm{S}_{0}\right)$, and $(\mathrm{c}-\mathrm{e})$ three different dihedral angles of $3 \mathrm{HQ}$.

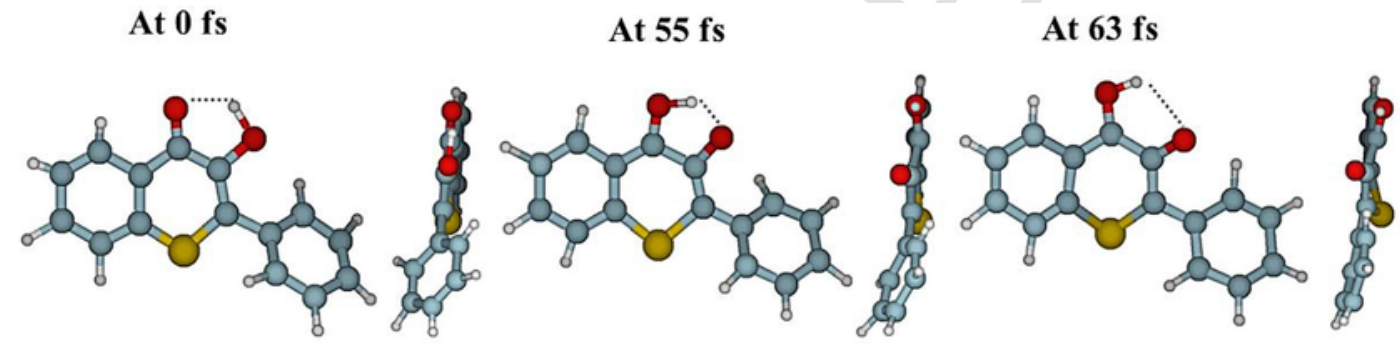

Fig. 10. Snapshots along with the ESIPT dynamic simulations at a different time of 3HTF (left: front view, right: side view).

\subsection{Dynamics simulations}

To obtain the information of the proton transfer, the $\mathrm{S}_{1}$ state dynamic simulations of $3 \mathrm{HF}, 3 \mathrm{HQ}, 3 \mathrm{HTF}$, and $3 \mathrm{HSO}$ were carried out using TD-B3LYP/TZVP level. Twenty-five trajectories as a representative set for each system were generated using a harmonic-oscillator Wigner distribution for each normal mode, as implemented in the NEWTON-X program [72,73] interfaced with the TURBOMOLE 6.3 program package [74]. Solving Newton's equation of nuclear motion was achieved by the Velocity-Verlet algorithm [22]. The Born-Oppenheimer energies and gradients were obtained at each time step by mean of the TD-B3LYP method, which has been tested and used in dynamic simulations in previous studies [60-62,66-68,75]. All trajectories for each complex were simulated with a time step of $1 \mathrm{fs}$ with the maximal duration of $500 \mathrm{fs}$, which is long enough to cover the pre- and post-PT regimes. In addition, each trajectory was categorized into two types of process: (1) 'ESIPT' when the PT process is observed and (2) 'No PT' when the PT process cannot be observed within the given simulation time. To obtain the dynamic information such as PT time (determined by the intersection point of average $\mathrm{O} 1 \cdots \mathrm{H} 1$ breaking and $\mathrm{O} 2 \cdots \mathrm{H} 1$ forming bond as a function of time), energy difference between the $\mathrm{S}_{0}$ and the $\mathrm{S}_{1}$ states, PT probabilities, and time evolutions in the $\mathrm{S}_{1}$ state on PT process, all active ESIPT trajectories were analyzed.

\section{Results and discussion}

\subsection{Effect of DFT functional}

The suitable choice of DFT and TD-DFT is very important to accurately explain the electronic structures, photophysical properties, and the occurrence of ESIPT process of $3 \mathrm{HF}$ and its analogues (3HQ, $3 \mathrm{HTF}$, and 3HSO). For choosing the suitable method, the structural optimization with seven different DFTs (B3LYP, PBE0, M06-2X, CAM-B3LYP, LC-BLYP, LC-BLYP $(\mu=0.200)$, and LC- $\omega$ PBE $(\mu=0.141)$ with TZVP basis set were carried out to obtain the $S_{0}$ structures and to reveal the functional influence on the enol absorption spectra of 3HF, 3HQ, 3HTF, and $3 \mathrm{HSO}$ using TD-DFT. The suitable method must provide good simulated result in term of reproducing the enol absorption spectra from the experimental data. The comparison of various TD-DFT calculations in terms of absorption $\left(\lambda_{\max }\right)$, oscillator strength $(f)$, and the deviation between the simulated and experimental absorption wavelength $(\Delta \lambda)$ of all investigated molecules in enol forms are listed in Table 1 and plotted in Fig. S1 in Electronic Supplementary Information (ESI). For 3HF, TD-B3LYP provides most agreement simulated absorption spectra compared to 

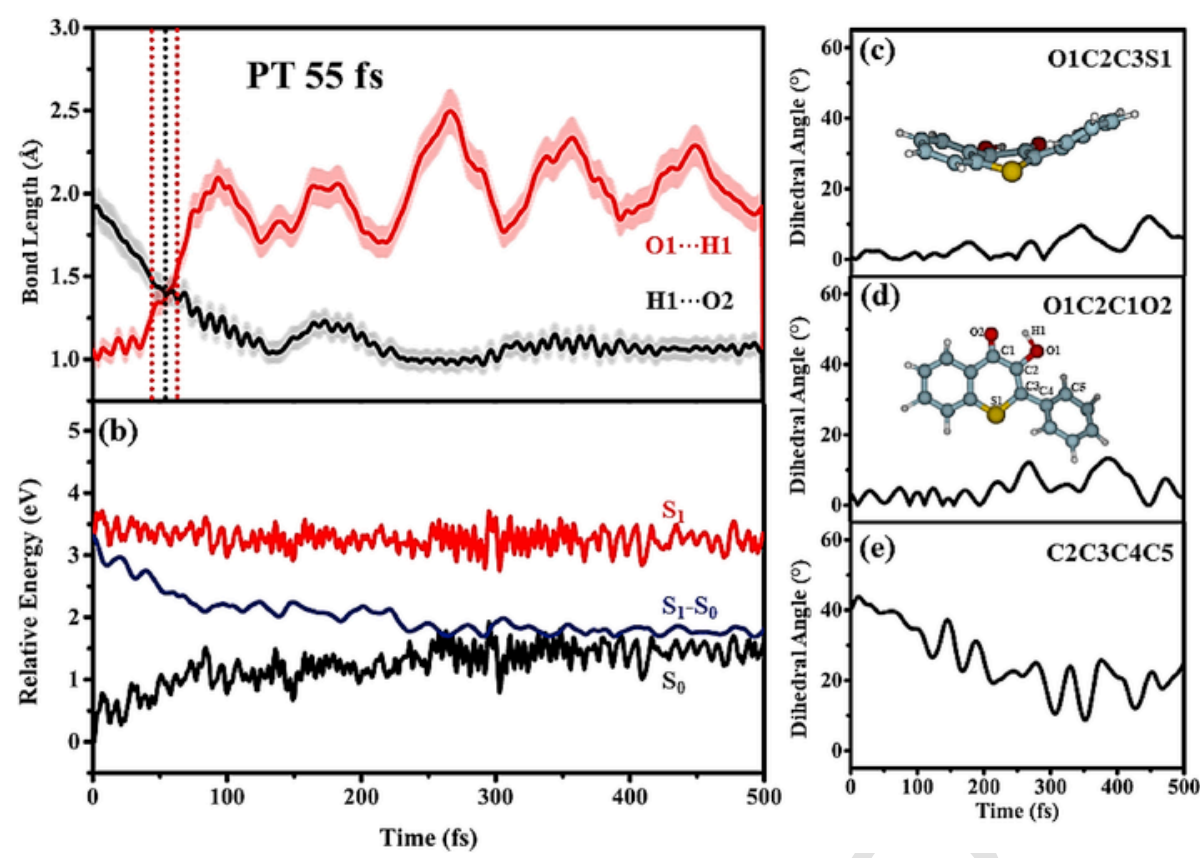

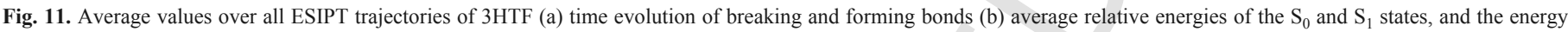
difference between the $S_{1}$ and $S_{0}$ states $\left(S_{1}-S_{0}\right)$, and (c-e) three different dihedral angles of $3 \mathrm{HTF}$.

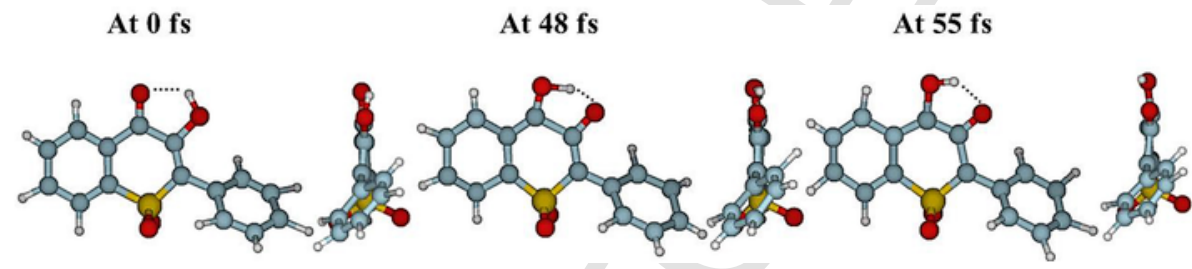

Fig. 12. Snapshots along with the ESIPT dynamic simulations at a different time of 3 HSO (left: front view, right: side view).

the absorption spectra from the experimental data with the smallest $\Delta \lambda$ value whereas, other functionals provide larger $\Delta \lambda$ values. For $3 \mathrm{HQ}$, the simulated enol absorption spectra from TD-B3LYP and TD-LC- $\omega$ PBE show good agreement with experimental data with small $\Delta \lambda$ values while other functionals show much larger values of $\Delta \lambda$. For 3HTF, the TD-B3LYP, TD-PBE0, TD-LC-B3LYP $(\mu=0.200)$, and TD-LC- $\omega$ PBE provide a small $\Delta \lambda$ value. Whereas, other functionals provide larger $\Delta \lambda$ values. Overall for the performance of all TD-DFT functionals, normal hybrid functions, both TD-B3LYP and TD-PBE0 functionals can explain electronic structures and photophysical properties of $3 \mathrm{HF}$ and its analogues. Meanwhile, long-range-corrected functionals either with a small or medium fraction of HF exchange fail to reproduce the experimental results. Accordingly, the popular TD-B3LYP provides the lowest average value of $\Delta \lambda$ and better-computed results compared to TD-PBE0. Therefore, TD-B3LYP is the most suitable method to further be used as a method to investigate the electronic structures, photophysical properties, and the ESIPT process of $3 \mathrm{HF}$ and its analogues.

\subsection{Optimized structure and H-bond strength supported by infrared spectra and topology analysis}

The optimized enol and keto forms of all molecules with labelling of all atoms and distances involved in the hydrogen bonding of the PT process are illustrated in Fig. 2 and Fig. S2 in ESI, respectively. For the enol forms, the covalent bond distances $(\mathrm{O} 1-\mathrm{H} 1)$, the in- tramolecular hydrogen distances $(\mathrm{O} 2 \cdots \mathrm{H} 1)$, the distances between heavy atoms $(\mathrm{O} 2 \cdots \mathrm{O} 1)$ connecting the intramolecular hydrogen bond, and the selected dihedral angle of enol and keto forms of $3 \mathrm{HF}, 3 \mathrm{HQ}$, $3 \mathrm{HTF}$, and $3 \mathrm{HSO}$ both in $\mathrm{S}_{1}$ and the $\mathrm{S}_{0}$ states are summarized in Table 2 and Table S2 in ESI, respectively. For the enol form of all molecules, the covalent bond distances $(\mathrm{O} 1-\mathrm{H} 1)$ of all molecules are lengthened from $0.978,0.980,0.981$, and $0.978 \AA$ in the $\mathrm{S}_{0}$ state to $0.999,0.995,1.008$, and $1.024 \AA$ in the $\mathrm{S}_{1}$ state, respectively. Whereas, the intramolecular hydrogen bond distances $(\mathrm{O} 2 \cdots \mathrm{H} 1)$ of all molecules are shortened from $2.012,1.994,1.909$, and $1.934 \AA$ in the $\mathrm{S}_{0}$ state to $1.847,1.888,1.730$, and $1.648 \AA$ in the $S_{1}$ state, respectively. In addition, the heavy atom distances $(\mathrm{O} 1 \cdots \mathrm{O} 2)$ of all molecules are also shortened from $2.625,2.620,2.554$, and $2.556 \AA$ in the $\mathrm{S}_{0}$ state to $2.541,2.561,2.473$, and $2.433 \AA$ in the $\mathrm{S}_{1}$ state, respectively. Moreover, the bond angle $\delta(\mathrm{O} 1-\mathrm{H} 1 \cdots \mathrm{O} 2)$ of $3 \mathrm{HF}, 3 \mathrm{HQ}, 3 \mathrm{HTF}$, and $3 \mathrm{HSO}$ increase from $118,119,121$, and $119^{\circ}$ in the $\mathrm{S}_{0}$ state to 123,122 , 127 , and $129^{\circ}$ in the $S_{1}$ state, respectively. In addition, the selected dihedral angles of all molecules change in the $S_{1}$ state compared to those in the $\mathrm{S}_{0}$ state. For example, $\mathrm{O} 1 \mathrm{C} 1 \mathrm{C} 2 \mathrm{X} 1$ dihedral angles increase from $0.7,1.5,0.1$, and $2.9^{\circ}$ in the $\mathrm{S}_{0}$ state to $1.1,2.8,10.6$, and $13.5^{\circ}$ in the $\mathrm{S}_{1}$ state for $3 \mathrm{HF}, 3 \mathrm{HQ}, 3 \mathrm{HTF}$, and $3 \mathrm{HSO}$, respectively. $\mathrm{O} 1 \mathrm{C} 1 \mathrm{C} 5 \mathrm{O} 2$ values of $3 \mathrm{HF}, 3 \mathrm{HQ}, 3 \mathrm{HTF}$, and $3 \mathrm{HSO}$ also increase from $0.3,0.6,0.7$, and $0.5^{\circ}$ in the $S_{0}$ state to $0.5,1.6,8.2$, and $8.3^{\circ}$ in the $\mathrm{S}_{1}$ state, respectively. The selected dihedral angles (C2C3C4C5) of all molecules decrease from 15.8, 40.2, 44.6, and $53.6^{\circ}$ in the $\mathrm{S}_{0}$ state to $0.06,26.8,23.6$, and $30.1^{\circ}$ in the $\mathrm{S}_{1}$ state, re- 

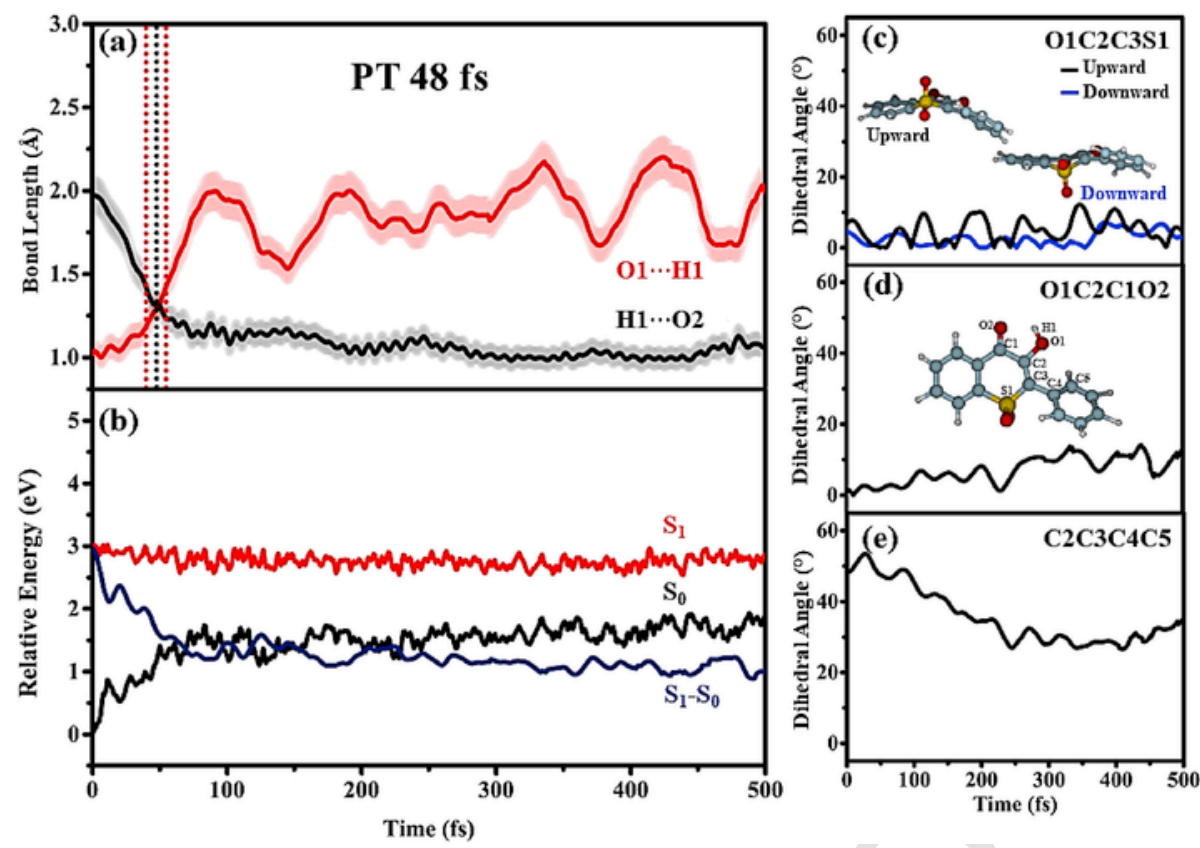

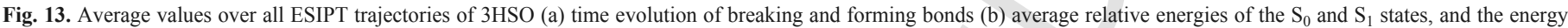
difference between the $\mathrm{S}_{1}$ and $\mathrm{S}_{0}$ states $\left(\mathrm{S}_{1}-\mathrm{S}_{0}\right)$, and (c-e) three different dihedral angles of $3 \mathrm{HSO}$.

spectively. These might be the effect of the heteroatom substitutions of $3 \mathrm{HF}$. Overall, the elongation of the covalent bond $(\mathrm{O} 1-\mathrm{H} 1)$, the shortening of the intramolecular hydrogen bond $(\mathrm{O} 2 \cdots \mathrm{H} 1)$ and the distance of the heavy atoms connecting proton donor and proton acceptor $(\mathrm{O} 1 \cdots \mathrm{O} 2)$, and the decrease in bond angle $\delta(\mathrm{O} 1-\mathrm{H} 1 \cdots \mathrm{O} 2)$ indicate that the intramolecular hydrogen bonds are strengthened in the $\mathrm{S}_{1}$ state. The strengthening of hydrogen bonds will be further confirmed by the IR spectra and topology analysis. Among 3HX analogues, $3 \mathrm{HSO}$ has the longest covalent bond distance, the shortest intramolecular hydrogen bond distance, and the shortest of the heavy atom distance both in $\mathrm{S}_{0}$ and $\mathrm{S}_{1}$ states, compared with other three molecules, these results suggest that the replacing of the $\mathrm{SO}_{2}$ group at $\mathrm{X}$ position in 3HX might increase the strengthening of the intramolecular hydrogen bond in $3 \mathrm{HSO}$ more than the other $3 \mathrm{HF}$ analogues.

To prove that the intramolecular hydrogen bond becomes strengthened upon photoexcitation, the IR spectra of $\mathrm{O} 1-\mathrm{H} 1$ stretching vibrational mode corresponding to the PT reaction coordinate both in $\mathrm{S}_{0}$ and $S_{1}$ states of all molecules are analyzed and shown in Fig. 3. The strengthening or weakening of the excited-state intramolecular hydrogen bond is considered through the red- or blue-shift of some important characteristic vibration modes, induced by the intramolecular hydrogen bond interactions which have been proposed by Han and co-worker $[59,76]$. For the enol form of $3 \mathrm{HF}$ in the $\mathrm{S}_{0}$ state, the simulated IR frequency of $\mathrm{O} 1-\mathrm{H} 1$ stretching mode is located at $3571 \mathrm{~cm}^{-1}$ in the $\mathrm{S}_{0}$ state and it decreased to around $3232 \mathrm{~cm}^{-1}$ in the $\mathrm{S}_{1}$ state with $339 \mathrm{~cm}^{-1}$ red-shift. Similarly, the O1-H1 stretching bands of enol form of $3 \mathrm{HQ}, 3 \mathrm{HTF}$, and $3 \mathrm{HSO}$ exhibit the red-shifts of 247, 446, and $716 \mathrm{~cm}^{-1}$, respectively. These results confirm that the intramolecular hydrogen bond of all molecules is strengthened in the $\mathrm{S}_{1}$ state. Among the four molecules, 3HSO shows the greatest red-shift of the O1-H1 stretching vibrational mode, which could be indicated that the replacing of the $\mathrm{SO}_{2}$ group as the least electronegativity at the $\mathrm{X}$ position of $3 \mathrm{HX}$ can enhance the intramolecular hydrogen bond strength. The strengthening of the intramolecular hydrogen bond is further confirmed by the topology analysis.
To obtain the strengthening of the intramolecular hydrogen bond between proton donor and proton acceptor as a bond critical point (BCP $[3,-1]$, type), the topological descriptors of the electron density $\rho(\mathrm{r})$, potential energy density $V(\mathrm{r})$, the Laplacian of the electron density $\nabla^{2} \rho(\mathrm{r})$, Lagrangian kinetic energy G(r), Hamiltonian kinetic energy density $\mathrm{H}(\mathrm{r})$, and the electron delocalization index between the proton acceptor and transferred proton (DI) of all molecules are analyzed and listed in Table 3. The value of $\rho(\mathrm{r})$ and the sign of $\nabla^{2} \rho(\mathrm{r})$ at $\mathrm{BCP}$ are closely related to the strengthening of the intramolecular hydrogen bond and bond type [77], respectively. The value of $V(\mathrm{r})$ at BCP is shown to be highly correlated with hydrogen bond energy [78]. The $\mathrm{H}(\mathrm{r})$ can be recovered by integrating from definitions is as follows:

$\mathrm{H}(\mathrm{r})=-1 / 2 \sum \eta_{\mathrm{i}} \phi_{\mathrm{i}} *(\mathrm{r}) \nabla^{2} \phi_{\mathrm{i}}(r)$

The value of $\mathrm{G}(\mathrm{r})$ is the shortcoming of $\mathrm{H}(\mathrm{r})$ which is not always positive and real. The definition that has more clear physical meaning is as follows:

$$
\mathrm{G}(\mathrm{r})=1 / 2 \sum \eta_{\mathrm{j}}\left|\nabla \phi_{\mathrm{i}}(\mathrm{r})^{2}\right|
$$

For another topological descriptor as DI, the larger the electron localization is in a region, the more likely the electron motion is confined within this value. If the electrons are completely localized, then they can be distinguished from the ones outside. The $V(r)$ is obtained from the relationships between the values of $\nabla^{2} \rho(r)$ and $G(r)$ as follows:

$V(\mathrm{r})=1 / 2 \nabla^{2} \rho(\mathrm{r})-2 \mathrm{G}(\mathrm{r})$ 
In addition, the value of $V(\mathrm{r})$ at BPC highly correlates with the hydrogen bond energy which is described as the Espinosa's equation:

$$
\mathrm{E}_{\mathrm{HB}}=1 / 2\left|V(\mathrm{r})_{\mathrm{BCP}}\right|
$$

The data in Table 3 indicate that the hydrogen bond energy of $3 \mathrm{HSO}$ is much higher than those of other $3 \mathrm{HF}$ analogues with the value of 0.028 a.u. The $V(\mathrm{r})$ of hydrogen bond becomes stronger gradually with the order of $3 \mathrm{HQ}>3 \mathrm{HF}>3 \mathrm{HTF}>3 \mathrm{HSO}$. The bigger values of the topological descriptors, the stronger the hydrogen bond. Therefore, the values of $\rho(\mathrm{r}), \mathrm{H}(\mathrm{r}), \mathrm{G}(\mathrm{r}), \nabla^{2} \rho(\mathrm{r})$, and DI comply with the order of $3 \mathrm{HSO}>3 \mathrm{HTF}>3 \mathrm{HF}>3 \mathrm{HQ}$, respectively. The results demonstrate that the intramolecular hydrogen bond of all molecules is strengthened in the $\mathrm{S}_{1}$ state which provides the possibility of the ESIPT via the BCP (listed in Table S3 in ESI).

\subsection{Electronic spectra and frontier molecular orbitals}

The simulated enol absorption (black line) and keto emission spectra of all molecules using TD-B3LYP/TZVP level which is the most suitable method are plotted in Fig. 4 (the dash lines used to represent the corresponding experimental values). The maximum wavelengths with oscillator strengths $(f)$, frontier molecular orbitals (MOs) contribution, and Stokes shifts of all molecules are summarized in Table 4.

From the data in Table 4, the simulated enol absorption maxima of $3 \mathrm{HF}, 3 \mathrm{HQ}, 3 \mathrm{HTF}$, and $3 \mathrm{HSO}$ are located at $343,362,371$, and $377 \mathrm{~nm}$, respectively, which agree well with the experimental values of 340 [25], 371 [43], 380 [44], and 370 [44] nm. Moreover, the keto emission maxima of $3 \mathrm{HF}, 3 \mathrm{HQ}, 3 \mathrm{HTF}$ and $3 \mathrm{HSO}$ are located at 528, 538, 638 , and $791 \mathrm{~nm}$, respectively. The simulated keto emission spectra are just slightly overestimated, compared with the experiment, which was observed at 525, 505, and $590 \mathrm{~nm}$ for $3 \mathrm{HF}, 3 \mathrm{HQ}$, and $3 \mathrm{HTF}$, respectively. Therefore, we ensure that TD-B3LYP/TZVP level is acceptable to describe the electronic structures and photophysical properties of all molecules. The enol absorption and keto emission of $3 \mathrm{HQ}$, $3 \mathrm{HTF}$, and $3 \mathrm{HSO}$ are red-shifted, compared with those of $3 \mathrm{HF}$. The deviations of $185,176,267$, and $414 \mathrm{~nm}$ for $3 \mathrm{HF}, 3 \mathrm{HQ}, 3 \mathrm{HTF}$, and $3 \mathrm{HSO}$, respectively, between the enol absorption and keto emission peak, are described as a large Stoke shift. The results indicate that the heteroatom substitution obviously provides the red-shift of enol absorption and keto emission leading to larger Stokes shift. Nevertheless, the keto emission of $3 \mathrm{HSO}$ could be not observed in the experiment. The reason for the observation might be from nonradiative relaxation which is further investigated by dynamics simulation and potential energy curve of the important dihedral angle.

To explore the intrinsic reason for the red-shift of enol absorption and keto emission, the calculated highest occupied molecular orbital (HOMO), the lowest unoccupied molecular orbital (LUMO) energy level, HOMO-LUMO gaps as well as frontier molecular orbitals (MOs) of enol and keto forms for all molecules are analyzed and illustrated in Fig. 5. Herein, the main electronic transition is associated with the orbitals in a range $97 \%-98 \%$ (HOMO $\rightarrow$ LUMO), which correspond to the dominant $\pi$ to $\pi^{*}$ transition or mixing with intramolecular charge transfer (ICT) transition depending on the heteroatom substitution. For the HOMO orbital, the electron density is distributed more on the phenyl moiety and partially on the pyran of $3 \mathrm{HF}$, pyridine of $3 \mathrm{HQ}$, thiopyran of $3 \mathrm{HTF}$, and thiopyran-4-one 1,1-dioxide ring of 3HSO. Whereas, in the LUMO orbital, the electron density completely occupies the whole molecule. The HOMO and
LUMO energy levels of 3HQ and 3HTF are higher than those of $3 \mathrm{HF}$. Meanwhile, the HOMO and LUMO energy levels of 3HSO are stabilized to be lower than those of 3HF because its nature of electronic transition upon photoexcitation is assigned to the combination of the $\pi$ to $\pi^{*}$ transition and ICT on the phenyl moiety and the thiopyran-4-one 1,1-dioxide ring which decrease dramatically the HOMO-LUMO gaps (see in Fig. 5).

Overall, the HOMO-LUMO gaps of enol and keto forms of $3 \mathrm{HQ}$, $3 \mathrm{HTF}$, and $3 \mathrm{HSO}$ are lower than that of $3 \mathrm{HF}$, leading to the red-shifts of the enol absorption and keto emission spectra. Moreover, upon photoexcitation, the electron density of carbonyl $(\mathrm{C}=\mathrm{O})$ group increases, which become more basic, and that of hydroxy $(-\mathrm{OH})$ group decreases, which become more acid, resulting in driving force to the ESIPT process through the intramolecular hydrogen bond between proton donor and proton acceptor groups.

\subsection{Potential energy curves of ESIPT reactions}

The PECs of PT reaction coordinates both in $\mathrm{S}_{0}$ and $\mathrm{S}_{1}$ states for all molecules are scanned and plotted in Fig. 6. The PT reaction energy $\left(\Delta \mathrm{E}_{\mathrm{rxn}}\right)$ in the $\mathrm{S}_{0}$ and $\mathrm{S}_{1}$ states is the energy differences between the optimized keto form (reactant) and enol form (product) without constraints. The PT barrier and $\Delta \mathrm{E}_{\mathrm{rxn}}$ of all molecules both in $\mathrm{S}_{0}$ and $\mathrm{S}_{1}$ states are summarized in Table 5 and plotted in Fig. S5 of the ESI. The PECs obtained from cost-effective B3LYP/TZVP level are reliable in providing qualitative energetic pathways for the ESIPT process, which has been used in the previous studies [62,70]. Moreover, the PECs from B3LYP and TD-B3LYP agree well with the PECs from higher level of calculation such as ADC(2)/cc-pVDZ (see Fig. S6 of the ESI). Therefore, TD-B3LYP method is suitable to describe the potential energy surface of the PT processes. The PT barriers in the $\mathrm{S}_{0}$ state are $13.13,11.65,12.56$, and $21.06 \mathrm{kcal} / \mathrm{mol}$ for $3 \mathrm{HF}, 3 \mathrm{HQ}, 3 \mathrm{HTF}$, and $3 \mathrm{HSO}$, respectively. While, the PT barriers of all molecules in the $\mathrm{S}_{1}$ state are $2.88,3.62,1.99$, and $0.87 \mathrm{kcal} / \mathrm{mol}$ for $3 \mathrm{HF}, 3 \mathrm{HQ}, 3 \mathrm{HTF}$, and $3 \mathrm{HSO}$, respectively. For the heteroatom substitution effect on the ESIPT process, the chance of ESIPT is found in this order: $3 \mathrm{HSO}>$ $3 \mathrm{HTF}>3 \mathrm{HF}>3 \mathrm{HQ}$. The $\mathrm{SO}_{2}$ group in $3 \mathrm{HX}$ can greatly encourage the ESIPT process.

Moreover, to evaluate ESIPT and the possibility of dual emission, PECs calculated along the reaction path optimized in the $\mathrm{S}_{0}$ and $\mathrm{S}_{1}$ states, and the vertical energy computed along the minimum reaction path both in the $S_{0}$ and $S_{1}$ states are plotted in Fig. 7. The calculated PECs and vertical excitation results of all studied molecules are in accordance with available experimental data. Overall, from the PECs, the PT processes of all molecules are most likely not to occur in the $\mathrm{S}_{0}$ state because the PT barriers are high with endothermic reaction. However, the PT processes of all molecules in the $\mathrm{S}_{1}$ state are spontaneous to take place because of their kinetically and thermodynamically favorable character (exothermic reaction with PT barriers less than $3 \mathrm{kcal} / \mathrm{mol}$ ). The possibility of the PT processes of all investigated molecules both in $\mathrm{S}_{0}$ and the $\mathrm{S}_{1}$ states will be confirmed by the excited-state dynamics simulations in the next section.

\subsection{Dynamic simulations}

The information of excited-state dynamics simulations, including the number of active trajectories, the probability of the PT process, the average time of the PT process of all molecules are performed and summarized in Table 6. Snapshots of average trajectories of $3 \mathrm{HQ}$, 3HTF, and $3 \mathrm{HSO}$ dynamics showing the time evolutions of the ESIPT reaction via intramolecular hydrogen bond are displayed in Figs. 8, 10 and 12, respectively (Fig. S7 in ESI for 3HF). The time 
evolution of the average distances of bond forming and breaking (shaded area as the average bonds referring to the time range of the proton being transferred), the potential energy of $\mathrm{S}_{1}$ and $\mathrm{S}_{0}$, and the $\mathrm{S}_{1}-\mathrm{S}_{0}$ energy difference, and three different dihedral angles of $3 \mathrm{HQ}$, 3HTF, and $3 \mathrm{HSO}$ for all ESIPT trajectories are analyzed and displayed in Figs. 9, 11 and 13, respectively (Fig. S8 in ESI for 3HF). Since the dynamic simulation of the PT process of $3 \mathrm{HF}$ was already reported in our previous work [61], so we will not discuss the dynamics information in this present work but only the comparison to $3 \mathrm{HQ}, 3 \mathrm{HTF}$, and $3 \mathrm{HSO}$ will be given.

\subsubsection{3-Hydroxyquinolone (3HQ)}

Six trajectories out of all trajectories for 3HQ show the ESIPT process (PT probability of 24\%) and 19 trajectories do not give PT process during the simulation time $(500 \mathrm{fs})$. The results of dynamics simulations indicate that the PT time constant is found at $70 \mathrm{fs}$ with the time range of 51-150 fs (Fig. 9a). The relative energy difference between the $S_{1}$ and $S_{0}\left(S_{1}-S_{0}\right)$ states as a blue line in Fig. $9 b$ is slightly decreased after the PT process (70 fs), this line decreases from above 3 to around $2 \mathrm{eV}$, implying that there is no skeleton change during the simulation time confirmed by no crossing between the $S_{1}$ and the $\mathrm{S}_{0}$ states. The average values of the interested dihedral angles $(\mathrm{O} 1 \mathrm{C} 2 \mathrm{C} 3 \mathrm{~N} 1$ and $\mathrm{O} 1 \mathrm{C} 2 \mathrm{C} 1 \mathrm{O} 2)$ slightly rise from around 5 to just below $10^{\circ}$ (Fig. $8 \mathrm{c}$ and d) while that of $\mathrm{C} 2 \mathrm{C} 3 \mathrm{C} 4 \mathrm{C} 5$ gradually decrease from around 30 to around $20^{\circ}$ (Fig. 9e). It is worth noting that once the PT process is complete within $70 \mathrm{fs}$, no major skeleton change of $3 \mathrm{HQ}$ is observed which is supported by the average $\mathrm{S}_{1}-\mathrm{S}_{0}$ energy lying around $2 \mathrm{eV}$ (no conical intersection between the $\mathrm{S}_{1}$ and the $\mathrm{S}_{0}$ states). Therefore, the keto emission will most likely to be observed, which is in accordance with the experimental data [44].

\subsubsection{3-Hydroxyhydroflavone (3HTF)}

For $3 \mathrm{HTF}$, twelve trajectories give the ESIPT process (PT probability of 0.48 ) and the other thirteen trajectories reveal no ESIPT process within the $500 \mathrm{fs}$. The PT time constant is found at $55 \mathrm{fs}$ within the time range of $45-63 \mathrm{fs}$ as shown in Fig. 11a. The relative energy difference between $\mathrm{S}_{1}$ and $\mathrm{S}_{0}$ states $\left(\mathrm{S}_{1}-\mathrm{S}_{0}\right)$ starts to gradually decrease in the first $100 \mathrm{fs}$ and it is kept just below $2 \mathrm{eV}$ during the simulation time as depicted in Fig. 11b. After the PT process, the average dihedral angles of $\mathrm{O} 1 \mathrm{C} 2 \mathrm{C} 3 \mathrm{~S} 1$ and $\mathrm{O} 1 \mathrm{C} 2 \mathrm{C} 1 \mathrm{O} 2$ increase moderately from 0 up to around $15^{\circ}$ (Fig. $11 \mathrm{c}$ and d) whereas that of $\mathrm{C} 2 \mathrm{C} 3 \mathrm{C} 4 \mathrm{C} 5$ decreases gradually from 0 to about $25^{\circ}$ (Fig. 11e). However, the overall dihedral angle changes do not effectively cause the crossing between $\mathrm{S}_{1}$ and $\mathrm{S}_{0}$ states. Like in the case of $3 \mathrm{HQ}$, the keto emission is observed in the experimental study [44].

\subsubsection{3-Hydroxy-2-phenyl-4H-thiochromen-4-one 1,1-dioxide (3HSO)}

For 3HSO, the ESIPT process of this molecule occurs in twenty-three trajectories (92\%) and only two trajectories show no ESIPT process within $500 \mathrm{fs}$. The dynamics simulations indicate that PT time takes place at 48 fs with the time range of 42-55 fs (Fig. 13a). The energy difference between the $S_{1}$ and $S_{0}$ states $\left(S_{1}-S_{0}\right)$ is reduced from approximately 3 to just above $1 \mathrm{eV}$ during the simulation time as shown in Fig. 13b. The $\mathrm{S}_{1}-\mathrm{S}_{0}$ energy drastically drops to below $1 \mathrm{eV}$, approaching the conical intersection between the $\mathrm{S}_{1}$ and $\mathrm{S}_{0}$ states which is in accordance with the average O1C2C3S1 dihedral angle (Fig. S9 in ESI). This dihedral angle fluctuates from 0 to $10^{\circ}$ depending on whether it is in the upward or downward direction (Fig. $13 \mathrm{c})$. The $\mathrm{O} 1 \mathrm{C} 2 \mathrm{C} 3 \mathrm{~S} 1$ dihedral angle remains constant around $5^{\circ}$ for the upward direction, however, that of the downward change slightly about $10^{\circ}$ after the PT process. For the $\mathrm{O} 1 \mathrm{C} 2 \mathrm{C} 1 \mathrm{O} 2$ and $\mathrm{C} 2 \mathrm{C} 3 \mathrm{C} 4 \mathrm{C} 5$ dihedral angles, they gradually start to increase from 0 to $15^{\circ}$ and decrease from around 50 to around $30^{\circ}$ (Fig. $13 \mathrm{~d}$ and e), respectively. Overall, the skeleton of $3 \mathrm{HSO}$ changes drastically during the simulation time and particularly after the PT has triggered, this leads to the crossing between the $S_{1}$ and $S_{0}$ states, resulting in the leaking of keto population in the $S_{1}$ state to $S_{0}$ (approaching conical intersection between the $S_{1}$ and the $S_{0}$ states) without giving any fluorescence even though the PT process of 3 HSO occurs readily. This finding agrees well with the no observation of keto emission reported [44].

\subsubsection{Comparative analysis}

Overall, the results from dynamic simulations obviously show that the ESIPT processes of $3 \mathrm{HQ}, 3 \mathrm{HTF}$, and $3 \mathrm{HSO}$ can take place and the PT time constants are found in this order; $3 \mathrm{HSO}$ (48 fs) $>3 \mathrm{HTF}$ $(55 \mathrm{fs})>3 \mathrm{HF}(60 \mathrm{fs})>3 \mathrm{HQ}(70 \mathrm{fs})$. Considering different $3 \mathrm{HX}$ analogues, $3 \mathrm{HF}, 3 \mathrm{HQ}, 3 \mathrm{HTF}$, and $3 \mathrm{HSO}$ with different heteroatoms at the $\mathrm{X}$-position $\left(\mathrm{X}=\mathrm{O}, \mathrm{N}, \mathrm{S}\right.$, and $\mathrm{SO}_{2}$, respectively), the PT time of $3 \mathrm{HSO}$ is faster than other analogues because of the least electron-donating capability of the $\mathrm{SO}_{2}$ compared to $\mathrm{O}, \mathrm{N}$, and $\mathrm{S}$ atoms. The Mulliken charges of all heteroatoms in the $3 \mathrm{HX}$ analogues both in $\mathrm{S}_{0}$ and $\mathrm{S}_{1}$ states are given in Figs. S2 and S3 of the ESI. The PT barriers attributing to the way of forming a keto form are well anti-correlated with PT probabilities. These PT barrier values assess the kinetically favorable direction of the reaction. The occurrence of ESIPT strongly depends on the electron-donating capacity of the heteroatom, the lesser electronegativity of heteroatom in the $3 \mathrm{HX}$, the faster ESIPT process. Furthermore, the PT probability anti-correlates with the PT barrier. The PT probability is found in this order; $3 \mathrm{HSO}$ $(92 \%)>3 \mathrm{HF}(76 \%)>3 \mathrm{HTF}(48 \%)>3 \mathrm{HQ}(24 \%)$. The occurrence of the ESIPT process relates well with the ESIPT reaction energy, the more exothermic reaction, the higher PT probability, however, the rate of the ESIPT process is generally irrelevant to this value.

\section{Conclusions}

The influence of heteroatom substitutions on the electronic structures, photophysical properties, and ESIPT processes of $3 \mathrm{HF}$ and its analogues (3HQ, 3HTF, and 3HSO) were systematically investigated using DFT and TD-DFT with B3LYP/TZVP level, which was validated to be the most suitable method in term of good agreement of simulated maxima wavelengths of enol absorption of all molecules with the experimental data. The conclusion can be summarized into two parts; static calculations and dynamics simulations.

For the static results, the intramolecular hydrogen bond distances of all molecules are strengthened in the $\mathrm{S}_{1}$ state, supported by the longer distances of the covalent bond $(\mathrm{O} 1-\mathrm{H} 1)$ and the shorter distances of the intramolecular hydrogen bond $(\mathrm{O} 2 \cdots \mathrm{H} 1)$ as well as the shorter distances of heavy atoms $(\mathrm{O} 1 \cdots \mathrm{O} 2)$ connecting the intramolecular hydrogen bond. The strengthening of the intramolecular hydrogen bond was further confirmed by the red-shift of IR spectra of $\mathrm{O} 1-\mathrm{H} 1$ stretching mode in the $\mathrm{S}_{1}$ state and the topology analysis. For the influence of heteroatom substitutions on the photophysical properties, the $\mathrm{N}$ and $\mathrm{S}$ substitutions raise the HOMO energy levels of 3HQ and 3HTF molecules more than their LUMO energy levels while the $\mathrm{SO}_{2}$ substitution stabilizes the LUMO energy level more than its HOMO energy level, leading to decreasing of the HOMO-LUMO gaps of $3 \mathrm{HF}$ analogues. As a result, the simulated enol absorption and keto emission spectra of $3 \mathrm{HF}$ analogues are shifted to longer wavelengths and relatively larger Stokes shifts. Moreover, frontier molecular orbitals (MOs) indicate that the charge redistribution between the proton donor and proton acceptor groups upon the photoexcitation induces the ESIPT process. Furthermore, 
the PECs of the PT process of all molecules reveal that the PT process in the $\mathrm{S}_{0}$ is unfavorable due to high PT barrier and endothermic reaction, but favorable in the $\mathrm{S}_{1}$ state because of low PT barriers and exothermic reaction.

For excited-state dynamics simulations, the results indicate that the ESIPT processes of all molecules easily occur via the intramolecular with the ultrafast time scale. The PT time values with the different heteroatoms in 3HX follow this order; 3HSO (48 fs) $>3$ HTF (55 $\mathrm{fs})>3 \mathrm{HF}(60 \mathrm{fs})>3 \mathrm{HQ}(70 \mathrm{fs})$ which is found anti-correlated with the electron-donating capacity of heteroatom. In addition, all results of static calculations of all molecules are in accordance with the dynamics simulations. However, the PT barrier is somehow not relevant to the probability of the PT process. Among all $3 \mathrm{HF}$ analogues, the PT process of $3 \mathrm{HSO}$ is easily facilitated because the $\mathrm{SO}_{2}$ group in $3 \mathrm{HSO}$ causes the strongest intramolecular hydrogen bond at the $\mathrm{S}_{1}$ state on the account of its shortest bond length $\mathrm{O} 2 \cdots \mathrm{H} 1$, the greatest red-shift of the $\mathrm{O} 1-\mathrm{H} 1$ stretching band, the topology analysis. Furthermore, the lowest PT barrier in the $\mathrm{S}_{1}$ state of 3HSO than those of $\mathrm{O}, \mathrm{N}$, and S-substituted molecules implies that the intramolecular charge transfer character (ICT), which is modulated by the $\mathrm{SO}_{2}$ group in $3 \mathrm{HX}$, can greatly contribute to the ESIPT process. Nevertheless, after ESIPT process is complete, the relative energy difference between $S_{1}$ and $S_{0}$ below $1 \mathrm{eV}$ found in $3 \mathrm{HSO}$ has indicated that the conical intersection between the ground and excited states has approached, leading to no keto emission observed in the experiment.

\section{Acknowledgements}

The authors wish to thank Thailand Research Fund (RTA6080005 and RSA6180044) for financial support. C. Sukpattanacharoen would like to thank The Science Achievement Scholarship of Thailand (SAST) for PhD fellowship. This research work was partially supported by Chiang Mai University. N. Kungwan would like to thank the Center of Excellence in Materials Science and Technology, Chiang Mai University for support. Computational Chemistry Laboratory Chiang Mai University (CCL-CMU), Department of Chemistry, Faculty of Science, and Graduate School, Chiang Mai University, Chiang Mai, Thailand are also acknowledged.

\section{Appendix A. Supplementary data}

Supplementary data to this article can be found online at https:// doi.org/10.1016/j.molstruc.2019.05.113.

\section{References}

[1] P. Zhou, K. Han, Unraveling the detailed mechanism of excited-state proton transfer, Accounts Chem. Res. 51 (7) (2018) 1681-1690.

[2] J.E. Kwon, S.Y. Park, Advanced organic optoelectronic materials: Harnessing excited-state intramolecular proton transfer (ESIPT) process, Adv. Mater. 23 (32) (2011) 3615-3642.

[3] J. Wu, W. Liu, J. Ge, H. Zhang, P. Wang, New sensing mechanisms for design of fluorescent chemosensors emerging in recent years, Chem. Soc. Rev. 40 (7) (2011) 3483-3495.

[4] S. Chaudhuri, A. Banerjee, K. Basu, B. Sengupta, P.K. Sengupta, Interaction of flavonoids with red blood cell membrane lipids and proteins: Antioxidant and antihemolytic effects, Int. J. Biol. Macromol. 41 (1) (2007) 42-48.

[5] L.M. Tolbert, K.M. Solntsev, Excited-state proton transfer: From constrained systems to "super" photoacids to superfast proton transfer, Accounts Chem. Res. 35 (1) (2002) 19-27.

[6] J. Zhao, S. Ji, Y. Chen, H. Guo, P. Yang, Excited state intramolecular proton transfer (ESIPT): From principal photophysics to the development of new chromophores and applications in fluorescent molecular probes and luminescent materials, Phys. Chem. Chem. Phys. 14 (25) (2012) 8803-8817.

[7] S.H. Kim, S. Park, J.E. Kwon, S.Y. Park, Organic light-emitting diodes with a white-emitting molecule: Emission mechanism and device characteristics, Adv. Funct. Mater. 21 (4) (2011) 644-651.
[8] Y. Wu, X. Peng, J. Fan, S. Gao, M. Tian, J. Zhao, S. Sun, Fluorescence sensing of anions based on inhibition of excited-state intramolecular proton transfer, J. Org. Chem. 72 (1) (2007) 62-70.

[9] A.C. Sedgwick, L. Wu, H.-H. Han, S.D. Bull, X.-P. He, T.D. James, J.L. Sessler, B.Z. Tang, H. Tian, J. Yoon, Excited-state intramolecular proton-transfer (ESIPT) based fluorescence sensors and imaging agents, Chem. Soc. Rev. 47 (23) (2018) 8842-8880.

[10] S. Ercelen, A.S. Klymchenko, A.P. Demchenko, Ultrasensitive fluorescent probe for the hydrophobic range of solvent polarities, Anal. Chim. Acta 464 (2) (2002) 273-287.

[11] D.A. Yushchenko, V.V. Shvadchak, A.S. Klymchenko, G. Duportail, V.G. Pivovarenko, Y. Mély, Modulation of excited-state intramolecular proton transfer by viscosity in protic media, J. Phys. Chem. A 111 (42) (2007) 10435-10438.

[12] M. Fischer, P. Wan, Nonlinear solvent water effects in the excited-state (formal) intramolecular proton transfer (ESIPT) in m-hydroxy-1, 1-diaryl alkenes: Efficient formation of m-quinone methides1, J. Am. Chem. Soc. 121 (19) (1999) 4555-4562.

[13] A.S. Klymchenko, A.P. Demchenko, Multiparametric probing of intermolecular interactions with fluorescent dye exhibiting excited state intramolecular proton transfer, Phys. Chem. Chem. Phys. 5 (3) (2003) 461-468.

[14] A.S. Klymchenko, A.P. Demchenko, Electrochromic modulation of excited-state intramolecular proton transfer: The new principle in design of fluorescence sensors, J. Am. Chem. Soc. 124 (41) (2002) 12372-12379.

[15] E. Oliveira, J. Lorenzo, A. Cid, J.L. Capelo, C. Lodeiro, Non-toxic fluorescent alanine-fluorescein probe with green emission for dual colorimetric/fluorimetric sensing, J. Photochem. Photobiol. A Chem. 269 (2013) 17-26.

[16] M. Beija, C.A. Afonso, J.M. Martinho, Synthesis and applications of rhodamine derivatives as fluorescent probes, Chem. Soc. Rev. 38 (8) (2009) 2410-2433.

[17] K. Sivakumar, F. Xie, B.M. Cash, S. Long, H.N. Barnhill, Q. Wang, A fluorogenic 1,3-dipolar cycloaddition reaction of 3-azidocoumarins and acetylenes, Org. Lett. 6 (24) (2004) 4603-4606.

[18] Z. Zhou, C.J. Fahrni, A fluorogenic probe for the copper(I)-catalyzed azide-alkyne ligation reaction: modulation of the fluorescence emission via $3\left(\mathrm{n}, \pi^{*}\right)-\left(\pi, \pi^{*}\right)$ inversion, J. Am. Chem. Soc. 126 (29) (2004) 8862-8863.

[19] F.J. Huo, J. Kang, C. Yin, J. Chao, Y. Zhang, Highly selective fluorescent and colorimetric probe for live-cell monitoring of sulphide based on bioorthogonal reaction, Sci. Rep. 5 (2015) 8969-8974.

[20] T.C. Hou, Y.Y. Wu, P.Y. Chiang, K.T. Tan, Near-infrared fluorescence activation probes based on disassembly-induced emission cyanine dye, Chem. Sci. 6 (8) (2015) 4643-4649.

[21] J. Guharay, B. Sengupta, P. Sengupta, Protein-flavonol interaction: Fluorescence spectroscopic study, Proteins: Struct. Funct. Bioinf. 43 (2) (2001) 75-81.

[22] B. Liu, H. Wang, T. Wang, Y. Bao, F. Du, J. Tian, Q. Li, R. Bai, A new ratiometric ESIPT sensor for detection of palladium species in aqueous solution, Chem. Commun. 48 (23) (2012) 2867-2869.

[23] B. Liu, Y. Pang, R. Bouhenni, E. Duah, S. Paruchuri, L. McDonald, A step toward simplified detection of serum albumin on SDS-PAGE using an environment-sensitive flavone sensor, Chem. Commun. 51 (55) (2015) 11060-11063.

[24] S. Chen, P. Hou, B. Zhou, X. Song, J. Wu, H. Zhang, J.W. Foley, A red fluorescent probe for thiols based on 3-hydroxyflavone and its application in living cell imaging, RSC Adv. 3 (29) (2013) 11543-11546.

[25] A.S. Klymchenko, A.P. Demchenko, 3-Hydroxychromone dyes exhibiting excited-state intramolecular proton transfer in water with efficient two-band fluorescence, New J. Chem. 28 (6) (2004) 687-692.

[26] Z. Szakács, M. Kállay, M. Kubinyi, Theoretical study on the photooxygenation and photorearrangement reactions of 3-hydroxyflavone, RSC Adv. 7 (51) (2017) 32185-32192.

[27] P.K. Sengupta, M. Kasha, Excited state proton-transfer spectroscopy of 3-hydroxyflavone and quercetin, Chem. Phys. Lett. 68 (2-3) (1979) 382-385.

[28] G.J. Woolfe, P.J. Thistlethwaite, Direct observation of excited state intramolecular proton transfer kinetics in 3-hydroxyflavone, J. Am. Chem. Soc. 103 (23) (1981) 6916-6923.

[29] Y. Jiang, Y. Peng, Excited-state intramolecular proton transfer reaction of 3-hydroxyflavone, J. Clust. Sci. 26 (6) (2015) 1983-1992.

[30] S.M. Ormson, R.G. Brown, F. Vollmer, W. Rettig, Switching between charge-and proton-transfer emission in the excited state of a substituted 3-hydroxyflavone, J. Photochem. Photobiol. A Chem. 81 (2) (1994) 65-72.

[31] A.S. Klymchenko, D.A. Yushchenko, Y. Mély, Tuning excited state intramolecular proton transfer in 3-hydroxyflavone derivative by reaction of its isothiocyanate group with an amine, J. Photochem. Photobiol. A Chem. 192 (2-3) (2007) 93-97.

[32] P.T. Chou, S.C. Pu, Y.M. Cheng, W.S. Yu, Y.C. Yu, F.T. Hung, W.P. Hu, Femtosecond dynamics on excited-state proton/charge-transfer reaction in 4 ' $-\mathrm{N}$, $\mathrm{N}$-diethylamino-3-hydroxyflavone. the role of dipolar vectors in constructing a rational mechanism, J. Phys. Chem. A 109 (17) (2005) 3777-3787.

[33] J. Han, X. Liu, C. Sun, Y. Li, H. Yin, Y. Shi, Ingenious modification of molecular structure effectively regulates excited-state intramolecular proton and charge transfer: A theoretical study based on 3-hydroxyflavone, RSC Adv. 8 (52) (2018) 29589-29597. 
[34] W. Zhang, B. Shi, J. Shi, Time-dependent density functional investigation on electronic spectra of 4'-N-dimethylamino-3-hydroxyflavone, J. Mol. Struct.: THEOCHEM 731 (1) (2005) 219-224.

[35] L. Jia, F. Wang, Y.J.O.E. Liu, Solvent effects on excited state intramolecular proton transfer mechanism in 4-(N, N-dimethylamino)-3-hydroxyflavone, Org Electron. 57 (2018) 292-297.

[36] A. Szalai, L. Giordano, V.M. Sánchez, T.D.Z. Atvars, M. Faleiros, E. Jares-Erijman, P.F. Aramendía, Temperature dependent spectroscopic and excited state dynamics of 3-hydroxychromones with electron donor and acceptor substituents, Methods Appl. Fluoresc. 5 (2) (2017), 024011-024023.

[37] L.G.T.A. Duarte, J.C. Germino, C.d.Á. Braga, C.A. Barboza, T.D.Z. Atvars, F.d.S. Santos, F.S. Rodembusch, Photoacidity as a tool to rationalize excited state intramolecular proton transfer reactivity in flavonols, Photochem. Photobiol. Sci. 17 (2) (2018) 231-238.

[38] A.S. Klymchenko, V.G. Pivovarenko, A.P. Demchenko, Elimination of the hydrogen bonding effect on the solvatochromism of 3-hydroxyflavones, J. Phys. Chem. A 107 (21) (2003) 4211-4216.

[39] V.G. Pivovarenko, O. Bugera, N. Humbert, A.S. Klymchenko, Y. Mély, A toolbox of chromones and quinolones for measuring a wide range of ATP concentrations, Chem. Eur. J. 23 (49) (2017) 11927-11934.

[40] D.A. Svechkarev, V.N. Baumer, Z.A. Syzova, A.O. Doroshenko, New benzimidazolic 3-hydroxychromone derivative with two alternative mechanisms of the excited state intramolecular proton transfer reaction, J. Mol. Struct. 882 (1) (2008) 63-69.

[41] L.V. Chepeleva, A.Y. Matsakov, Z.A. Kondratyuk, F.G. Yaremenko, A.O. Doroshenko, Pyrazolyc 3-hydroxychromones: Regulation of ESIPT reaction by the "flavonol-like" intramolecular hydrogen bonding to carbonyl group oxygen, which dominates over the "alternative" H-bond to heterocyclic nitrogen, J. Photochem. Photobiol. A Chem. 209 (2) (2010) 163-173.

[42] D. Svechkarev, A. Doroshenko, V. Baumer, B. Dereka, Nature of dual fluorescence in 2-(quinolin-2-yl)-3-hydroxychromone: Tuning between concurrent H-bond directions and ESIPT pathways, J. Lumin. 131 (2) (2011) 253-261.

[43] F. Gao, K.F. Johnson, J.B. Schlenoff, Ring closing and photooxidation in nitrogen analogues of 3-hydroxyflavone, J. Chem. Soc. Perkin Trans. 2 (2) (1996) 269-273.

[44] F.Y. Meng, Y.A. Chen, C.L. Chen, P.T. Chou, Syntheses and excited-state intramolecular proton transfer of 3-hydroxythioflavone and its sulfone analogue, ChemPhotoChem 2 (6) (2018) 475-480.

[45] C. Sun, H. Zhao, X. Liu, H. Yin, Y. Shi, Tunable ESIPT reaction and antioxidant activities of 3-hydroxyflavone and its derivatives by altering atomic electronegativity, Org. Chem. Front. 5 (23) (2018) 3435-3442.

[46] A.D. Becke, Density-functional thermochemistry. III. the role of exact exchange J. Chem. Phys. 98 (7) (1993) 5648-5652.

[47] C. Adamo, V. Barone, Toward reliable density functional methods without adjustable parameters: The PBE0 model, J. Chem. Phys. 110 (13) (1999) 6158-6170.

[48] Y. Zhao, D.G. Truhlar, The M06 suite of density functionals for main group thermochemistry, thermochemical kinetics, noncovalent interactions, excited states, and transition elements: Two new functionals and systematic testing of four M06-class functionals and 12 other functionals, Theor. Chem. Accounts 120 (1-3) (2008) 215-241.

[49] A.D. Becke, Density-functional thermochemistry. V. systematic optimization of exchange-correlation functionals, J. Chem. Phys. 107 (20) (1997) 8554-8560.

[50] H. Iikura, T. Tsuneda, T. Yanai, K. Hirao, A long-range correction scheme for generalized-gradient-approximation exchange functionals, J. Chem. Phys. 115 (8) (2001) 3540-3544

[51] T. Leininger, H. Stoll, H.J. Werner, A. Savin, Combining long-range configuration interaction with short-range density functionals, Chem. Phys. Lett. 275 (3-4) (1997) 151-160.

[52] T.M. Henderson, B.G. Janesko, G.E. Scuseria, Generalized gradient approximation model exchange holes for range-separated hybrids, J. Chem. Phys. 128 (19) (2008) 194105-194115.

[53] T. Körzdörfer, J.S. Sears, C. Sutton, J.L. Brédas, Long-range corrected hybrid functionals for $\pi$-conjugated systems: Dependence of the range-separation parameter on conjugation length, J. Chem. Phys. 135 (20) (2011) 204107-204114.

[54] A. Schäfer, C. Huber, R. Ahlrichs, Fully optimized contracted Gaussian basis sets of triple zeta valence quality for atoms Li to Kr, J. Chem. Phys. 100 (8) (1994) 5829-5835.

[55] B. Mennucci, J. Tomasi, R. Cammi, J. Cheeseman, M. Frisch, F. Devlin, S. Gabriel, P. Stephens, Polarizable continuum model (PCM) calculations of solvent effects on optical rotations of chiral molecules, J. Phys. Chem. A 106 (25) (2002) 6102-6113.

[56] N.M. O'Boyle, J.G. Vos, A.L. Tenderholt, K.M. Langner, GaussSum 3.0, J. Comput. Chem. 29 (2008) 839-845.

[57] S. Takeuchi, T. Tahara, Coherent nuclear wavepacket motions in ultrafast excited-state intramolecular proton transfer: sub-30-fs resolved pump-probe ab- sorption spectroscopy of 10-hydroxybenzo[h]quinoline in solution, J. Phys Chem. A 109 (45) (2005) 10199-10207.

[58] M. Zhou, J. Zhao, Y. Cui, Q. Wang, Y. Dai, P. Song, L. Xia, Theoretical study on the excited-state intramolecular proton-transfer reaction of 10-hydroxybenzo[h]quinoline in methanol and cyclohexane, J. Lumin. 161 (2015) 1-6.

[59] Y. Yang, Y. Liu, D. Yang, H. Li, K. Jiang, J. Sun, Photoinduced excited state intramolecular proton transfer and spectral behaviors of aloesaponarin 1, Spectrochim. Acta Mol. Biomol. Spectrosc. 151 (2015) 814-820.

[60] C. Prommin, N. Kanlayakan, W. Chansen, R. Salaeh, K. Kerdpol, R. Daengngern, N. Kungwan, Theoretical Insights on solvent control of intramolecular and intermolecular proton transfer of 2-(2'-hydroxyphenyl) benzimidazole, J. Phys. Chem. A 121 (31) (2017) 5773-5784.

[61] R. Salaeh, C. Prommin, W. Chansen, K. Kerdpol, R. Daengngern, N. Kungwan, The effect of protic solvents on the excited state proton transfer of 3-hydroxyflavone: A TD-DFT static and molecular dynamics study, J. Mol. Liq. 252 (2018) 428-438.

[62] W. Chansen, R. Salaeh, C. Prommin, K. Kerdpol, R. Daengngern, N. Kungwan, Theoretical study on influence of geometry controlling over the excited-state intramolecular proton transfer of 10-hydroxybenzo [h] quinoline and its derivatives, Comput. Theor. Chem. 1113 (2017) 42-51.

[63] T. Lu, F. Chen, Multiwfn: A multifunctional wavefunction analyzer, J. Comput. Chem. 33 (5) (2012) 580-592.

[64] Y. Li, K. Wen, S. Feng, H. Yuan, B. An, Q. Zhu, X. Guo, J. Zhang, Tunable excited-state intramolecular proton transfer reactions with $\mathrm{NH}$ or $\mathrm{OH}$ as a proton donor: A theoretical investigation, Spectrochim. Acta Mol. Biomol. Spectrosc. 187 (2017) 9-14.

[65] Q. Zhang, H. Kuwabara, W.J. Potscavage Jr., S. Huang, Y. Hatae, T. Shibata, C. Adachi, Anthraquinone-based intramolecular charge-transfer compounds: Computational molecular design, thermally activated delayed fluorescence, and highly efficient red electroluminescence, J. Am. Chem. Soc. 136 (52) (2014) 18070-18081.

[66] R. Daengngern, N. Kungwan, Electronic and photophysical properties of 2 -(2'-hydroxyphenyl) benzoxazole and its derivatives enhancing in the excited-state intramolecular proton transfer processes: A TD-DFT study on substitution effect, J. Lumin. 167 (2015) 132-139.

[67] N. Kanlayakan, K. Kerdpol, C. Prommin, R. Salaeh, W. Chansen, C. Sattayanon, N. Kungwan, Effects of different proton donor and acceptor groups on excited-state intramolecular proton transfers of amino-type and hydroxy-type hydrogen-bonding molecules: Theoretical insights, New J. Chem. 41 (17) (2017) 8761-8771.

[68] K. Kerdpol, R. Daengngern, N. Kungwan, Excited-state proton-transfer reactions of 7-azaindole with water, ammonia and mixed water-ammonia: Microsolvated dynamics simulation, Mol. Simul. 41 (14) (2015) 1177-1186.

[69] N. Kungwan, F. Plasser, A.J. Aquino, M. Barbatti, P. Wolschann, H. Lischka, The effect of hydrogen bonding on the excited-state proton transfer in 2-(2'-hydroxyphenyl) benzothiazole: A TDDFT molecular dynamics study, Phys. Chem. Chem. Phys. 14 (25) (2012) 9016-9025.

[70] N. Manojai, R. Daengngern, K. Kerdpol, C. Ngaojampa, N. Kungwan, Heteroatom effect on photophysical properties of 2-(2'-hydroxyphenyl) benzimidazole and its derivatives as fluorescent dyes: A TD-DFT study, J. Lumin. 188 (2017) 275-282

[71] M.J. Gwt, H.B. Frisch, G.E. Schlegel, M.A. Scuseria, J.R. Robb, G. Cheeseman, V. Scalmani, B. Barone, G.A. Mennucci, H. Petersson, Gaussian 09, Revision A. 01, Gaussian Inc., Wallingford, 2009.

[72] M. Barbatti, G. Granucci, M. Persico, M. Ruckenbauer, M. Vazdar, M. Eckert-Maksić, H. Lischka, The on-the-fly surface-hopping program system Newton-X: Application to ab initio simulation of the nonadiabatic photodynamics of benchmark systems, J. Photochem. Photobiol. A Chem. 190 (2-3) (2007) 228-240.

[73] M. Barbatti, G. Granucci, M. Ruckenbauer, F. Plasser, J. Pittner, M. Persico, H. Lischka, Newton-X: A Package for Newtonian Dynamics Close to the Crossing Seam, Max-Planck-Institut für Kohlenforschung: Mülheim an der Ruhr, Germany, 2011 version 1.2

[74] R. Ahlrichs, M. Bär, M. Häser, H. Horn, C. Kölmel, Electronic structure calculations on workstation computers: The program system turbomole, Chem. Phys. Lett. 162 (3) (1989) 165-169.

[75] R. Daengngern, N. Kungwan, Dynamics simulations of photoinduced proton transfer reactions of 2-(2'-hydroxyphenyl)benzoxazole in the gas phase and its hydrated clusters, Chem. Phys. Lett. 609 (2014) 147-154

[76] C. Sun, H. Li, H. Yin, Y. Li, Y. Shi, Effects of the cyano substitution at differen positions on the ESIPT properties of alizarin: A DFT/TD-DFT investigation, J. Mol. Liq. 269 (2018) 650-656.

[77] R. Bader, Atoms in Molecules. A Quantum Theory, International Series of Monographs on Chemistry Clarendon Press, Oxford, 1994.

[78] E. Espinosa, E. Molins, C. Lecomte, Hydrogen bond strengths revealed by topological analyses of experimentally observed electron densities, Chem. Phys. Lett. 285 (3) (1998) 170-173. 